\title{
RAPIDS evaluation final report 2005-2009 key findings
}

\author{
Louis Apicella \\ Population Council \\ Katie D. Schenk \\ Population Council \\ Hena Khan \\ Population Council
}

Follow this and additional works at: https://knowledgecommons.popcouncil.org/departments_sbsr-hiv

Part of the Community Health and Preventive Medicine Commons, Demography, Population, and Ecology Commons, Health Services Research Commons, Immune System Diseases Commons, International Public Health Commons, Maternal and Child Health Commons, Medicine and Health Commons, Virus Diseases Commons, and the Women's Health Commons How does access to this work benefit you? Let us know!

\section{Recommended Citation}

Louis Apicella, Katie D. Schenk, and Hena Khan. 2010. "RAPIDS evaluation final report 2005-2009 key findings." Lusaka: Population Council. 


\section{RAPIDS Evaluation Final Report 2005-2009 Key Findings}

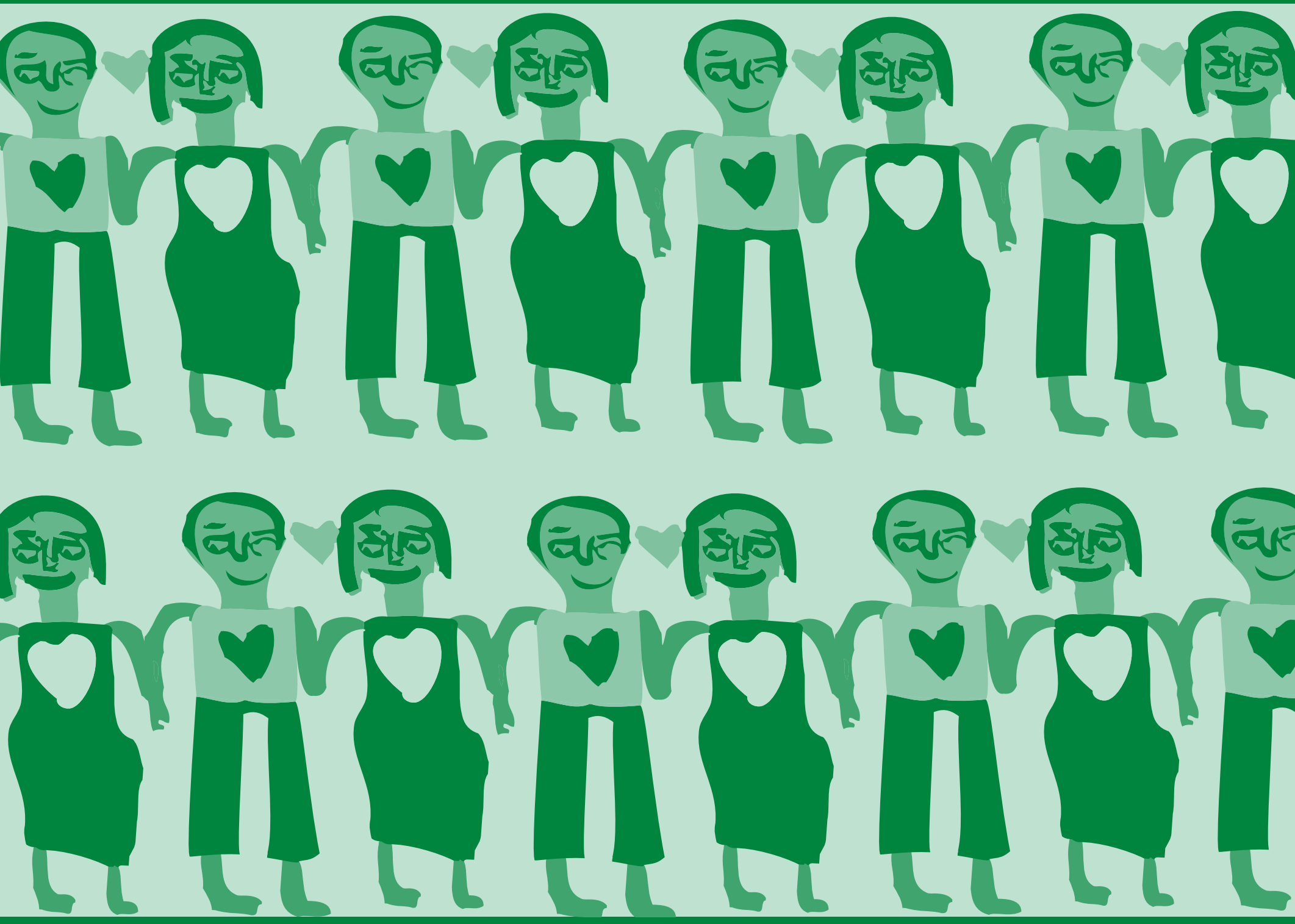

Read more about this study at www.popcouncil.org/RAPIDS 



\section{RAPIDS Evaluation Final Report 2005-2009}

\section{Key Findings}
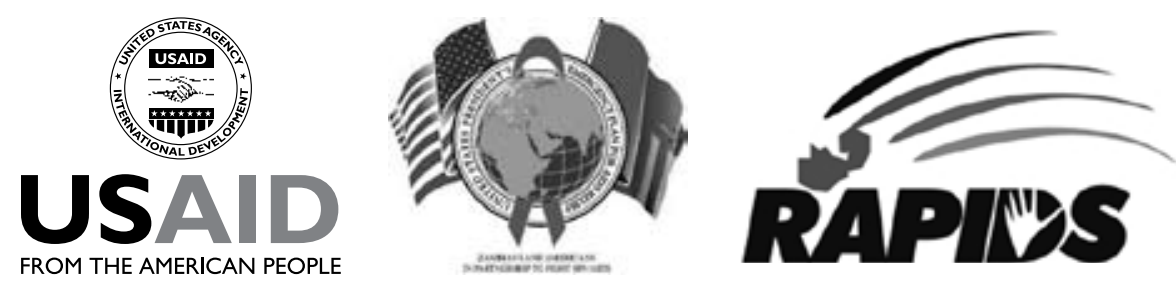

(1) Population Council

July 2009

Revised 2010 


\section{(2) Population Council}

in partnership with



Contracted by

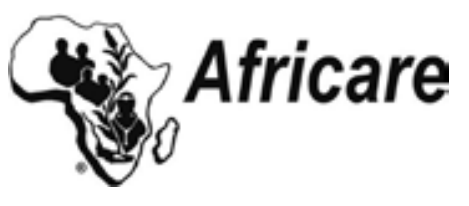

On behalf of

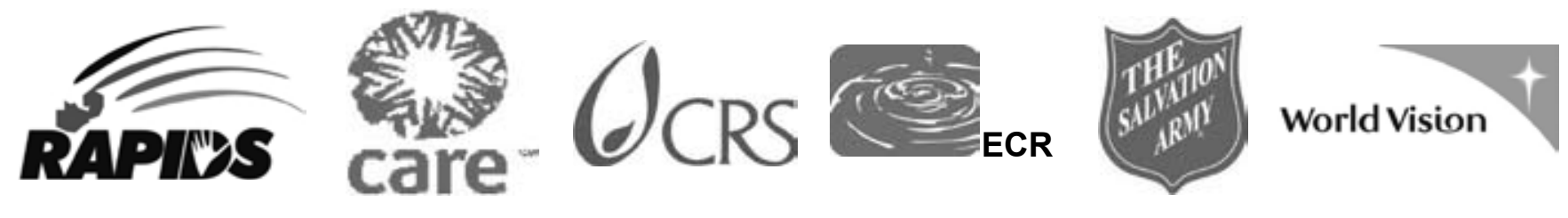




\section{TABLE OF CONTENTS}

ABBREVIATIONS V v v v v v v v

EXECUTIVE SUMMARY

$\begin{array}{ll}\text { Methods } & 1\end{array}$

Key findings $\quad 1$

$\begin{array}{ll}\text { Conclusion } & 4\end{array}$

$\begin{array}{ll}\text { INTRODUCTION } & 5\end{array}$

$\begin{array}{lr}\text { EVALUATION AIMS } & 6\end{array}$

$\begin{array}{ll}\text { METHODS } & 7\end{array}$

KEY FINDINGS $\quad 9$

SO 1: School attendance among orphans and vulnerable children improved during study period

SO 1: Coverage of RAPIDS educational and psychosocial support services expanded during study period

SO 2: Advent of treatment expanded caregiver role to include adherence support

SO 2: Stigma lessening, especially in RAPIDS households

SO 2: HIV testing significantly higher among RAPIDS households

SO 1 and 2: Caregiver visits increased significantly

SO 1 and 2: Recipients reported positive experience of caregiver visits

SO 1 and 2: Caregivers cite need for additional supplies, training and support for themselves and clients

SO 1 and 2: Distribution of gifts-in-kind reflected program supplies more than client needs

SO 1 and 2: Client selection for distribution of goods and services improving and addressing challenges

SO 3: Unmarried youth respond to abstinence messages but need continued encouragement and reinforcement 
SO 3: Secondary abstinence among female youth increased significantly over study period

SO 3: Youth emphasize preference for income generating activities over life skills training

SO 4: RAPIDS households demonstrated better food security, but demand remains high

Other important findings from the evaluation

SUSTAINABILITY

RECOMMENDATIONS

Strategic objective 1: Improve quality of life of orphans and vulnerable children and their households

Strategic objective 2: Improve quality of life of people living with HIV/AIDS

Strategic objective 3: Improve livelihoods for vulnerable youth

Strategic objective 4: Strengthen resilience of households made vulnerable by HIV / AIDS

Other program recommendations 


\section{ABBREVIATIONS}

AIDS Acquired immune deficiency syndrome

ARV Antiretroviral drugs

CBO Community-based organization

CRS Catholic Relief Services

DATF District AIDS Taskforce

ECR Expanded Church Response Trust

FBO Faith-based organization

FGD Focus group discussion

GIK Gifts-in-kind

GRZ Government of the Republic of Zambia

HBC Home-based care

HEPS High energy protein supplement

HIV Human immunodeficiency virus

IDI In-depth interview

IEC Information, Education and Communication

KII Key Informant Interview

NGO Non-governmental organization

OVC Orphans and vulnerable children

PC Population Council

PEPFAR President's Emergency Plan for AIDS Relief

PMU Program Management Unit

RAPIDS Reaching HIV/AIDS Affected People with Integrated Development and Support

RHH RAPIDS Household

ToT Trainer of trainers

TSA The Salvation Army

USAID United States Agency for International Development

USD United States Dollar

USG United States Government

WVI World Vision International 
vi a RAPIDS Evaluation Final Report 2005-2009 Key Findings 


\section{EXECUTIVE SUMMARY}

RAPIDS, which stands for Reaching HIV/AIDS Affected People with Integrated Development and Support, funded by the United States Agency for International Development (USAID), is an intervention designed to mitigate the impact of HIV/AIDS in Zambia. RAPIDS comprises a consortium of implementing partners led by World Vision International (WVI) together with Africare, CARE Zambia, Catholic Relief Services (CRS), Expanded Church Response Trust (ECR), and The Salvation Army (TSA).

The overall goal of RAPIDS is to improve the quality of life of Zambians affected by HIV and AIDS by expanding successful community-based models of home-based care and support to orphans and vulnerable children and people who are chronically ill, as well as through interventions targeting youth with livelihood opportunities and life-skills training, focusing on initiatives supporting abstinence and being faithful.

\section{Methods}

From among all the sites where RAPIDS programmatic activities take place, the project partners, in consultation with Population Council, selected six districts that represented a variety of settings and activities of the RAPIDS Consortium for an evaluation of the program's impact. The six districts selected were: Chongwe (Lusaka Province), Kalomo (Southern Province), Mazabuka (Southern Province), Mpika (Northern Province), Ndola (Copperbelt Province) and Petauke (Eastern Province).

The evaluation was a three-round cross-sectional population-based study, including qualitative and quantitative components at each round. Baseline data collection was conducted in May 2005, midterm in April 2007 after an interval of 23 months, and endline in March 2009, after a further 23 months. Full details of study methods, including ethical approvals, sampling procedures and analysis can be found in the RAPIDS Midterm Report ${ }^{1}$. The evaluation, conducted by Population Council with local research partner RuralNet Associates, is summarized in this report.

\section{Key findings}

\section{Strategic objective 1-Improve quality of life of orphans and vulnerable children and their households}

The evaluation found that school attendance among orphans and vulnerable children improved during the study period. By the midterm and endline surveys, data indicate that overall school attendance

${ }^{1}$ RAPIDS Midterm Report, Population Council, December 2007, Washington DC and Lusaka 
was increasing, and that the educational disadvantage (i.e., lower school attendance rates) suffered by children who have been orphaned and rendered vulnerable was getting smaller, especially among boys. Evaluation data also found that coverage of RAPIDS educational and psychosocial support services expanded during study period. Between baseline and endline, the coverage of educational support services among eligible households increased significantly across all study sites, from a total of 10 percent of eligible households at baseline up to 19 percent of eligible households at endline. During the same period, coverage of psychosocial support services increased dramatically from 3 percent across all sentinel sites at baseline to 20 percent at endline. The coverage of OVC caregiver visits among eligible households between baseline and endline showed significant expansion, increasing from 7 to 17 percent overall. During the same period, among households who reported receiving caregiver visits to support OVC or chronically ill individuals over the prior six months, the mean number of reported visits during the preceding six months increased significantly from 2.3 visits at baseline to 10.9 visits at endline. Sixty-nine percent of respondents reported that the caregivers had brought changes to the household, a significant improvement from 53 percent at baseline $(p<0.01)$.

\section{Recommendations}

The RAPIDS Consortium successfully delivered and continually expanded household services to orphans and vulnerable children. Quantitative data and qualitative feedback both indicate that increasing caregiver frequency and length of visits has a very positive effect on the household's member's quality of life. This is in line with the recommendations from past evaluations to continue refining the household support model to service delivery. Furthermore, psychosocial support from caregivers as well as gifts in kind associated with the schooling requirements were very successful in raising the quality of life of OVCs via school attendance. The RAPIDS Consortium should consider continuing to spend effort acquiring school items that are needed by OVCs.

\section{Strategic objective 2-Improve quality of life of people living with HIV/AIDS}

As national ART scale-up has progressed, caregivers have faced new demands from their clients to respond to their questions about treatment, address their concerns, and support their adherence to ART. Comments from caregivers, clients and program staff indicate that the RAPIDS program has recognized this important expansion of the caregivers' role by providing training in treatment support and adherence. Survey data over the study period indicate that the percentage of respondents who were aware of stigmatizing behaviors in the community dropped throughout the study sites over time. By 2009, awareness of these stigmatizing behaviors was measured below 10 percent across all sites, levels so low that the detection of further improvement may be practically impossible. When asked about their personal beliefs about AIDS, survey respondents from RAPIDS households indicated a much sharper decline in stigmatizing beliefs than those from non-RAPIDS households, reflecting the anti-stigma campaigning messages of RAPIDS intervention activities are taking root in their households. Furthermore, the evaluation found that HIV testing was significantly higher among RAPIDS households. Logistic regression determined that, at midterm, respondents from RAPIDS households were 36 percent more likely to have ever been tested for HIV (OR 1.36 [95\% CI:1.03-1.81]; $\mathrm{p}>0.031)$ than respondents from non-RAPIDS households. At endline, respondents from RAPIDS households were 24 percent more likely to ever have been tested for HIV (OR 1.24 [95\% CI:1.00-1.56]; $\mathrm{p}>0.054)$. Caregivers also requested greater attention from RAPIDS to regularly 
replenish their supplies - especially the contents of their caregiver kits-in order to enable them to provide a better service to their clients. Caregivers indicated that they valued the training they had received from RAPIDS, and underscored the importance of training in psychosocial support. They requested ongoing and refresher training sessions to continue to improve the quality of the caregiving duties that they perform. However, by far the most requested training content was to provide skills in income generation for the post-RAPIDS future, for both caregivers and their clients.

\section{Recommendations}

The RAPIDS Consortium's caregiving services to people who are chronically ill must continue to address the changing needs of people living with HIV and AIDS as the availability of ART expands in Zambia. Continual access to counseling and testing services, especially offered at home simultaneously to the couple, remains important as a first step towards destigmatization and accessing treatment. As a result of a successful caregiver program and the rehabilitation of the household, RAPIDS must prepare for an increase in demand for palliative care, especially physical therapy, as clients live longer and develop later stages of the chronic symptoms of HIV/AIDS.

\section{Strategic objective 3-Improve livelihoods for vulnerable youth}

Among the male youth covered in the household survey, involvement in RAPIDS livelihoods activities, including vocational skills training (tailoring, knitting, carpentry and catering) and micro- enterprise development, increased significantly during the evaluation period, from 20 percent at baseline to 38 percent at endline. However, participation of females in livelihoods activities appeared to lag behind, remaining stable at 15-17 percent when compared to their male peers. Both male and female youth living in households who reported receiving RAPIDS services in the past 6 months showed a much higher rate of reporting that they had participated in any income-generating activities; females significantly so $(24$ percent vs. 11 percent, $\mathrm{p}<0.000)$.

\section{Recommendations}

The RAPIDS Consortium should explore creative new ways to create opportunities for youth to utilize their skills, including access to capital and experienced business leaders. Advanced vocational training to top graduates could be a way to seed business leaders in the communities. Young women are not accessing livelihoods training opportunities as well as their male counterparts, indicating a need for the RAPIDS Consortium to revisit programs activities in relation to the needs of females and their possible employment opportunities.

\section{Strategic objective 4-Strengthen resilience of households made vulnerable by HIV/ AIDS}

Among households supporting someone who is chronically ill or a child who had been orphaned or taken in, coverage of RAPIDS food support services such as beans, maize, cooking oil or kapenta, increased from 10 percent to 13 percent overall. During the same period, data show that the demand for food support was consistently high-up to 90 percent of households surveyed requested food 
support at endline.

\section{Recommendations}

With the continued vulnerability of female-headed households indicated through asset ownership and food security, RAPIDS Consortium partners are urged to maintain attention to programming that will provide particular support to female-headed households and households who lack healthy adult caregivers. The role of food support and supplementary food interventions is especially important to meet the nutritional requirements of people on ART. Caregivers should have additional training on how best to advise their clients on nutritional intake. More focused IGA activities, increased caregiver visits, especially in households who are missing one or more healthy adult caregiver are crucial to the households' success.

\section{Conclusion}

This evaluation of the RAPIDS program has demonstrated that the implementation of a large-scale complex integrated intervention can make significant progress towards addressing the circumstances of families and communities affected by HIV in a high-prevalence area. This study has indicated a number of important practical lessons relevant for the management of interventions focusing on the care and support of families affected by HIV in Zambia and beyond. It has also demonstrated the importance of sound evaluation for documenting processes and outcomes associated with a programmatic intervention, in order to inform donor priorities. Continued research into evaluating other combinations of interventions to address the needs of vulnerable families living in high HIV prevalence areas remains crucial to informing donor spending. 


\section{INTRODUCTION}

RAPIDS, which stands for Reaching HIV/AIDS Affected People with Integrated Development and Support, is a US-funded intervention designed to mitigate the impact of HIV/AIDS in Zambia. RAPIDS comprises a consortium of implementing partners led by World Vision International (WVI) together with Africare, CARE Zambia, Catholic Relief Services (CRS), Expanded Church Response Trust (ECR), and The Salvation Army (TSA).

The overall goal of RAPIDS is to improve the quality of life of Zambians affected by HIV and AIDS by expanding successful community-based models of home-based care and support to orphans and vulnerable children and people who are chronically ill, as well as through interventions targeting youth with livelihood opportunities and life-skills training, focusing on initiatives supporting abstinence and being faithful.

RAPIDS has the following four strategic objectives:

- SO1-Improve quality of life of orphans and vulnerable children and their households;

- SO2-Improve quality of life of people living with HIV/AIDS;

- SO3-Improve livelihoods for vulnerable youth; and

- SO4-Strengthen resilience of households made vulnerable by HIV/AIDS.

RAPIDS interventions include children's schooling support (books, uniforms, school fees, transport to school), material support (shoes, clothes, other gifts-in-kind), psychosocial support (spiritual, emotional, general counseling), house building or repair, home visits to support children who have been orphaned or rendered vulnerable (OVC), home visits to support people who are chronically ill (home-based care/HBC), the provision of food support for HIV-positive clients (beans, maize, cooking oil, kapenta), and supplementary food (HEPS, soy mince). These interventions take place on a national scale, operating in 52 of the 72 districts and covering all nine provinces of Zambia by 2009. Interventions include training and subgrants to 295 community and faith-based organizations throughout Zambia.

From among all the sites where RAPIDS programmatic activities take place, the project partners, in consultation with Population Council, selected six districts that represented a variety of settings and activities of the RAPIDS Consortium for an evaluation of the program's impact. That evaluation, conducted by Population Council with local research partner RuralNet Associates, is summarized in this report. 


\section{EVALUATION AIMS}

This evaluation of the RAPIDS program aimed to assess the operations and impacts of the RAPIDS interventions, in order to inform ongoing program activities, improve service quality and model future program directions by determining whether the RAPIDS interventions raised the wellbeing of the community as a whole. The evaluation was designed to measure impact through a set list of core indicators gathered via quantitative and qualitative surveys that were developed in conjunction with the RAPIDS Consortium partners at the outset of the evaluation.

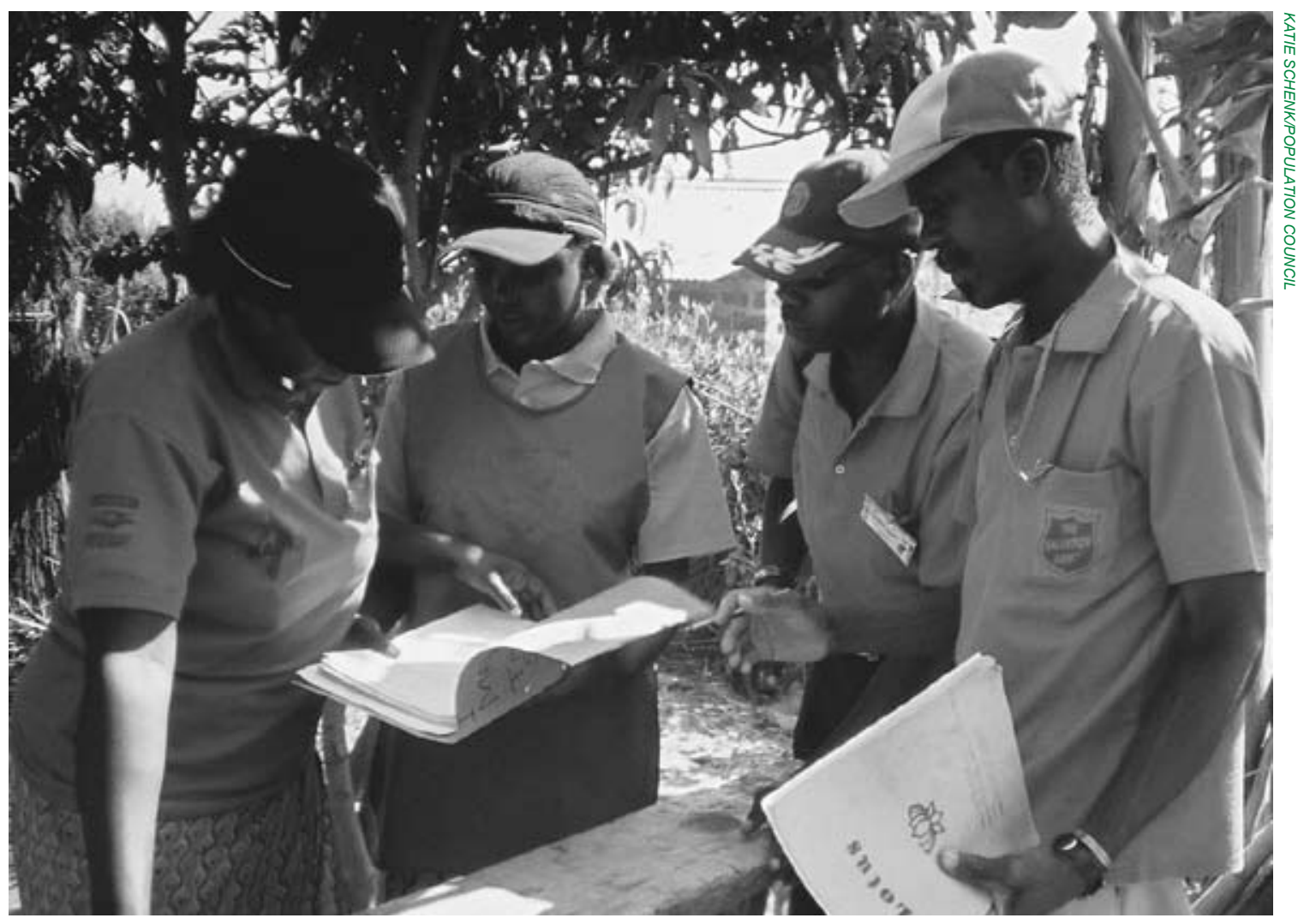

RAPIDS caregivers review client notes 


\section{METHODS}

The evaluation was a three-round cross-sectional population-based study, including qualitative and quantitative components at each round. Baseline data collection was conducted in May 2005, midterm in April 2007 after an interval of 23 months, and endline in March 2009, after a further 23 months. The study was conducted at sites in six districts that were selected by RAPIDS Consortium partners to represent geographical and culturally diverse areas in which multiple combinations of RAPIDS Consortium partners and interventions would be operational in the first year of RAPIDS implementation. The six districts selected were: Chongwe (Lusaka Province), Kalomo (Southern Province), Mazabuka (Southern Province), Mpika (Northern Province), Ndola (Copperbelt Province) and Petauke (Eastern Province).

Households in the survey were drawn from all households in the community (i.e., not just those eligible for or receiving services). Multi-level cluster sampling was employed in order to provide an accessible and affordable way to reach sampled households. The total target sample size for the survey among household heads was set at 250 households per district, or 1,500 households total across all six sites, in order to detect significant changes in the core indicators (e.g., school attendance) in each site over the three survey rounds between baseline in 2005 and the final round in 2009. Full details of study methods, including ethical approvals, sampling procedures and analysis can be found in the RAPIDS Midterm Report ${ }^{2}$.

For the purposes of the household survey, a "RAPIDS household" (RHH) is defined as one in which the respondent reported receiving at least one service (schooling support, material support, psychosocial support, house building/repair, home visits for OVC, HBC support, food support, or supplementary food) from at least one of the RAPIDS partners at least once during the preceding six months. It should be noted that RAPIDS households are inherently worse off than other households in their communities as the criteria established to receive RAPIDS services is based on selecting the households with the greatest need, so it is to be expected that they are by nature generally worse off than other households within the community. Because of this, raising the level of the RAPIDS household to that of a household not receiving RAPIDS services can be defined as a success.

The quantitative component was primarily based upon survey responses with the household head. Additional surveys were conducted with children (aged 10-14) and youths (aged 15-24) living within the household, to reflect the intended target recipients of the different RAPIDS interventions (Table 1). Because of variation in the populations, the interventions taking place at each site, and implementing partners, results in the two previous reports were presented by district at the request of the partners, so that each partner could monitor outcomes in their sentinel district over each round of the evaluation and to take account of district variation. As a result of feedback from the RAPIDS Consortium on the midterm report and subsequent discussions with the partners, it was decided that the Consortium would be better served if the final evaluation results were aggregated across all six sites and categorized according to whether household members reported that they were recipients of

${ }^{2}$ RAPIDS Midterm Report, Population Council, December 2007, Washington DC and Lusaka. 
RAPIDS services or not, in order to directly inform the Consortium as to the effects of their program. As a result of this change in report structure, results are no longer presented by district.

There are many explanations for observed differences between RAPIDS and non-RAPIDS households. The results shown here are an aggregate picture of the effects of the RAPIDS Consortium's interventions across all six districts, with considerable underlying variation by partner and by site. The effects of receiving the different components of the RAPIDS interventions differ at each location. There are also many other external changes happening simultaneously at the study sites, including increasing access to antiretroviral treatment and other programmatic activities from other organizations. Since the RAPIDS services are focused upon reaching the most vulnerable households, RAPIDS households were worse-off than other households at the time that the study began, and these differences may continue even if RAPIDS brings significant improvements.

Table 1 Quantitative data-Demographic description of survey respondents^

\begin{tabular}{lccc}
\hline & Baseline & Midterm & Endline \\
& May 2005 & April 2007 & March 2009 \\
\hline Household survey respondents & 1,267 & 1,423 & 1,710 \\
& $52 \% \mathrm{M}$ & $43 \% \mathrm{M}$ & $41 \% \mathrm{M}$ \\
Children aged 0-18 years living with household & $48 \% \mathrm{~F}$ & $57 \% \mathrm{~F}$ & $59 \% \mathrm{~F}$ \\
survey respondents & 4,254 & 4,209 & 5,440 \\
& $51 \% \mathrm{M}$ & $51 \% \mathrm{M}$ & $50 \% \mathrm{M}$ \\
Youth survey respondents aged 15-24 years & $49 \% \mathrm{~F}$ & $49 \% \mathrm{~F}$ & $50 \% \mathrm{~F}$ \\
& 439 & 346 & 483 \\
Child survey respondents aged 10-14 years & $50 \% \mathrm{M}$ & $51 \% \mathrm{M}$ & $47 \% \mathrm{M}$ \\
& $50 \% \mathrm{~F}$ & $49 \% \mathrm{~F}$ & $53 \% \mathrm{~F}$ \\
& 562 & 375 & 643 \\
& $48 \% \mathrm{M}$ & $46 \% \mathrm{M}$ & $45 \% \mathrm{M}$ \\
\hline
\end{tabular}

${ }^{\wedge}$ Growth in sample size reflects improvements in efficiency of data collection and the need for increased numbers to run logistic models.

The qualitative research component was designed to provide further detailed insights into service delivery procedures and quality, using tools developed with the active participation of RAPIDS Consortium staff in the field and at headquarters. Focus group discussions and in-depth interviews concentrated on three districts representing all RAPIDS Consortium partners and program activities (Kalomo, Mpika, Ndola). Participants of the qualitative research activities at all three rounds included RAPIDS clients, youths, program volunteers (caregivers, trainers, peer educators), staff, stakeholders, and non-clients. Emergent themes and illustrative quotes referred to in this report are from the endline activities in March 2009 ( $\mathrm{n}=31$ for focus group discussions and in-depth interviews, among a total of 191 participants at 3 sites). At endline, key informant interviews with seven GRZ and USAID officials provided valuable information and insight into the achievement of RAPIDS' strategic objectives. 


\section{KEY FINDINGS}

\section{SO 1: School attendance among orphans and vulnerable children improved during study period}

Males 7-18 in RAPIDS households showed an increasing school attendance from baseline to endline (83 percent to 89 percent).

- Females 7-18 in RAPIDS households showed increasing school attendance from baseline to endline (78 percent to 87 percent).

At midterm, children of RAPIDS households were 49 percent more likely to attend school.

- At endline, children of RAPIDS households were 44 percent more likely to attend school.

School attendance among children aged 7-18 was examined in two ways: firstly, by exploring trends at individual level (separately analyzing every child living within the household), and secondly by exploring trends at household level (analyzing all children in each household together). The household analysis was introduced in order to control for household factors that may affect individual school attendance and mask program effects.

Data on individual children from the household survey indicated that at baseline, orphans and vulnerable children of both sexes had lower school attendance rates than other children. By the midterm and endline surveys, data indicate that overall school attendance was increasing, and that the educational disadvantage (i.e., lower school attendance rates) suffered by children who have been orphaned and rendered vulnerable was getting smaller, especially among boys. At midterm and endline, boys of school-going age living in households that reported receiving RAPIDS services in the past six months were significantly more likely to be currently attending school than those from non-RAPIDS households. Girls living in RAPIDS households were also more likely to attend school, although these numbers did not reach statistical significance (all p-values $\geq 0.30$ ) (Table 2 and Figure 1).

Table 2 School attendance among children ages 7-18

\begin{tabular}{lcc|cc}
\hline & \multicolumn{2}{c|}{ Males } & \multicolumn{2}{c}{ Females } \\
& $\begin{array}{c}\text { non-RHH } \\
\%\end{array}$ & $\begin{array}{c}\text { RHH } \\
\%\end{array}$ & $\begin{array}{c}\text { non-RHH } \\
\%\end{array}$ & $\begin{array}{c}\text { RHH } \\
\%\end{array}$ \\
\hline Baseline 2005 & $\mathrm{n}=139$ & $\mathrm{n}=211$ & $\mathrm{n}=124$ & $\mathrm{n}=210$ \\
& $\mathbf{8 4}$ & $\mathbf{8 3}$ & $\mathbf{7 5}$ & $\mathbf{7 8}$ \\
Midterm 2007 & $\mathrm{n}=190$ & $\mathrm{n}=332$ & $\mathrm{n}=172$ & $\mathrm{n}=248$ \\
& $\mathbf{7 8}$ & $\mathbf{8 8}^{* *}$ & $\mathbf{8 0}$ & $\mathbf{8 4}$ \\
Endline 2009 & $\mathrm{n}=186$ & $\mathrm{n}=654$ & $\mathrm{n}=195$ & $\mathrm{n}=570$ \\
\hline
\end{tabular}

${ }^{*} p \leq 0.05,{ }^{* *} p<0.01$ comparing non-RAPIDS to RAPIDS households 
Figure 1 School attendance among children ages 7-18

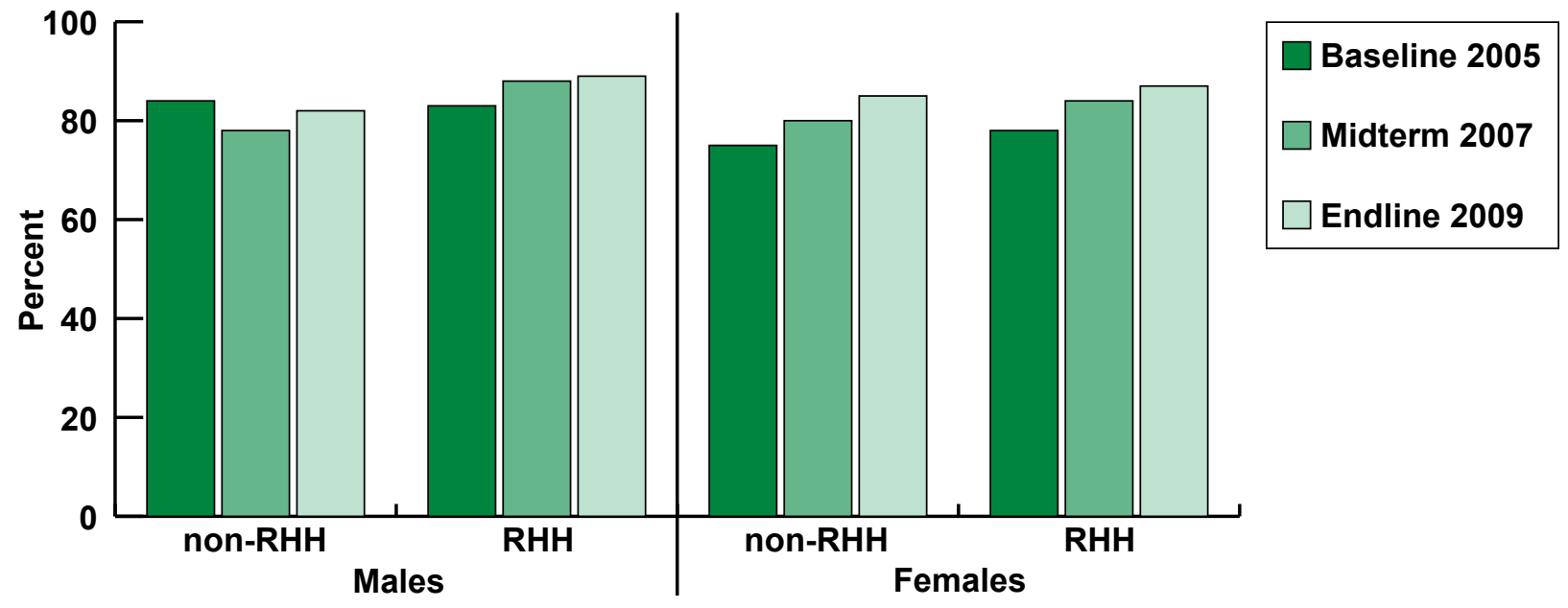

Logistic regression was used to examine the differences between households in which all children of school-going age were currently attending school and households in which some children were out of school. The model controlled for sex of household head, respondent characteristics (age, marital status, education), and household composition (number of adults and children, if the household includes a child who has been orphaned or taken in, or an individual who is chronically ill). At baseline there was no difference between RAPIDS and non-RAPIDS households, as expected, since services had just been initiated. At midterm, RAPIDS households were 49 percent more likely than non-RAPIDS households to report that all school-aged children in the household were currently attending school (OR 1.49 [95\% CI:1.05-2.12]; $\mathrm{p}>0.027$ ); and at endline, RAPIDS households were 44 percent more likely than non-RAPIDS households (OR 1.44 [95\% CI:1.10-1.90]; $\mathrm{p}>0.011$ ) to report that all schoolaged children living within the household were currently attending school.

\section{SO 1: Coverage of RAPIDS educational and psychosocial support services expanded during study period}

- Coverage of educational support services increased from 10 percent to 19 percent of eligible households.

- Coverage of psychosocial support services increased from 3 percent to 20 percent of eligible households.

RAPIDS educational support services include the provision of school fees and school requirements (e.g., uniforms, books, pens) provided to households in which there is a child who has been orphaned or taken in. RAPIDS psychosocial support services include the provision of emotional and spiritual counseling to households whose members include vulnerable children and people who are chronically ill. Additional RAPIDS interventions in the community that were not directly evaluated by the household surveys included support to community schools. 
Between baseline and endline, the coverage of educational support services among eligible households increased significantly across all study sites, from a total of 10 percent of eligible households at baseline up to 19 percent of eligible households at endline (Table 3). During the same period, coverage of psychosocial support services increased dramatically from 3 percent across all sentinel sites at baseline to 20 percent at endline. The expansion of these services took place within a context of high and increasing demand for these services among a consistently vulnerable population.

Table 3 Coverage of RAPIDS support services among eligible households

\begin{tabular}{lccc}
\hline $\begin{array}{l}\text { \% of eligible households that have received support for } \\
\text { indicated service }\end{array}$ & $\begin{array}{c}2005 \\
\%\end{array}$ & $\begin{array}{c}2007 \\
\%\end{array}$ & $\begin{array}{c}2009 \\
\%\end{array}$ \\
\hline Number of eligible households (with OVC) & $\mathrm{n}=625$ & $\mathrm{n}=570$ & $\mathrm{n}=761$ \\
Educational support & 10 & 13 & $19^{* *}$ \\
OVC caregiver visits & 7 & 9 & $17^{* *}$ \\
Number of eligible households (with OVC or PLHA) & $\mathrm{n}=726$ & $\mathrm{n}=658$ & $\mathrm{n}=862$ \\
Psychosocial support & 3 & 15 & $20^{* *}$ \\
Food support & 10 & 12 & 13 \\
Number of eligible households (with PLHA) & $\mathrm{n}=233$ & $\mathrm{n}=187$ & $\mathrm{n}=240$ \\
HBC caregiver visits & 12 & 12 & 15 \\
\hline
\end{tabular}

${ }^{*} p \leq 0.05,{ }^{* *} p<0.01$ comparing baseline to endline only

\section{SO 2: Advent of treatment expanded caregiver role to include adherence support}

The RAPIDS program has been operating within a dynamic context of expanding ART roll-out throughout Zambia. As national ART scale-up has progressed, caregivers have faced new demands from their clients to respond to their questions about treatment, address their concerns, and support their adherence to ART. Comments from caregivers, clients and program staff indicate that the RAPIDS program has been responsive to these emergent concerns, recognizing this important expansion of the caregivers' role by providing training in treatment support and adherence. Caregivers testify that their duties now include monitoring client intake of ARV drugs and training another household member to provide ongoing treatment support to the client.

"They [caregivers] belp you know where to go and also where and when to get $A R V$ s."

Female client, Mpika 
"I was trained in the one about drinking medicine, adherence. So we teach them about drinking medicine — that they should drink medicine according to the times they were told to drink. We also encourage the clients that they will not die but will get better, because even I am on the same medication. So they feel happy to know that what affects them also affects us."

Male caregiver, Kalomo

"We do need some more training. In 2007, when we were trained in adherence, talking about the side effects of $A R V$ s, this helped us to understand the side effects associated with $A R V$ s. We were grateful for this knowledge as advising clients became easier."

Female caregiver, Ndola

\section{SO 2: Stigma lessening, especially in RAPIDS households}

Stigma is lessening significantly throughout the entire community

- At endline, RAPIDS households were significantly less likely to exhibit stigmatizing behaviors towards HIV infected members of their community

Survey data over the study period indicate that the percentage of respondents who were aware of stigmatizing behaviors in the community dropped throughout the study sites over time. Fewer community members reported that they were aware of people living with HIV being ostracized (such as being made to eat alone), which represents a general move towards more positive and supportive attitudes (Table 4). By 2009, awareness of these stigmatizing behaviors was measured below 10 percent across all sites, levels so low that the detection of further improvement may be practically impossible. As expected, there were no significant differences between RAPIDS and non-RAPIDS households (data not shown), because this is a community-wide measure.

Table 4 Awareness of stigmatizing behaviors in the community

\begin{tabular}{lccc}
\hline Respondent knows personally someone who... & 2005 & 2007 & 2009 \\
& $\mathrm{n}=1,267$ & $\mathrm{n}=1,423$ & $\mathbf{n}=\mathbf{1 , 7 1 0}$ \\
\hline ...abandoned by their family & 11 & 10 & $9^{*}$ \\
...made to eat alone & 13 & 9 & $9^{* *}$ \\
...is no longer visited at home & 8 & 7 & 7 \\
...excluded from a social gathering & 7 & 4 & $4^{*}$ \\
\hline
\end{tabular}

${ }^{*} p<0.05,{ }^{* *} p<0.01$ comparing baseline to endline only 
Meanwhile, when asked about their personal beliefs about AIDS, survey respondents from RAPIDS households (reporting receiving RAPIDS services at least once during the last six months) indicated a much sharper decline in stigmatizing beliefs than those from non-RAPIDS households, reflecting the anti-stigma campaigning messages of RAPIDS intervention activities are taking root in their households (Table 5).

Table 5 Stigmatizing personal beliefs about AIDS

\begin{tabular}{lcc|cc|cc}
\hline Respondent agrees that ... & \multicolumn{2}{c|}{2005} & \multicolumn{2}{c|}{2007} & \multicolumn{2}{c}{2009} \\
& $\mathrm{nRHH}$ & $\mathrm{RHH}$ & $\mathrm{nRHH}$ & $\mathrm{RHH}$ & $\mathrm{nRHH}$ & $\mathrm{RHH}$ \\
& $\mathrm{n}=1,046$ & $\mathrm{n}=221$ & $\mathrm{n}=1,118$ & $\mathrm{n}=305$ & $\mathrm{n}=1,188$ & $\mathrm{n}=522$ \\
\hline $\begin{array}{l}\text { AIDS is a punishment for bad } \\
\text { behavior }\end{array}$ & 55 & 52 & 52 & 51 & 53 & $44^{* *}$ \\
$\begin{array}{l}\text { People with AIDS deserve what } \\
\text { they get }\end{array}$ & 37 & 41 & 30 & 28 & 33 & $27^{* *}$ \\
$\begin{array}{l}\text { Would feel ashamed if someone } \\
\text { from family got AIDS }\end{array}$ & 27 & $19^{* *}$ & 17 & 16 & 20 & $15^{* *}$ \\
$\begin{array}{l}\text { Would not buy food from seller } \\
\text { with AIDS because of fear they } \\
\text { might get it }\end{array}$ & 38 & 36 & 20 & 19 & 22 & 20 \\
\hline
\end{tabular}

${ }^{*} p<0.05,{ }^{* *} p<0.01$ comparing $n R H H$ vs $\mathrm{RHH}$ only

Comments from qualitative research participants suggest that the effects of stigma are lessening, although not gone. Over the study period, there was no change in respondent perceptions of how the community feels about people living with HIV and their children: almost a third of respondents still felt that the community treats children whose parents are sick or have died of HIV/AIDS differently.

"Stigma is there, among the youth and the adults. I can give an example - Africare recently organized a mobile VCT program and they wanted as many young people as possible. You would find that people, especially the young people, were not coming and when you asked around they would say 'the moment people see me entering that VCT room, they will assume that I am HIV positive or sexually active.' This was the reason for people not coming for testing and counseling. It's all stigma — people fear to be judged even before results come out for going for VCT.”

Program staff, Kalomo

Comments from qualitative research also suggested that people are less afraid to disclose that they are HIV-positive. These changes are associated with bringing VCT to the household, expansion of ARV treatment and continuing public sensitization campaigns. This changing context has had positive effects for the household visits of caregivers, who are now welcomed by clients previously afraid that 
neighbors would become suspicious, and who are now able to work together with previously hostile family members to help them to care for the sick person in their household.

"Stigma is reducing seriously. It is ending. People approach us freely."

Male caregiver, Kalomo

"When we just started, I was turned away by some HBC clients—they were afraid that their neighbours would know that they are HIV positive if they see a caregiver coming to their home. However this is a thing of the past, and people are more willing to allow us at their homes."

Female caregiver, Kalomo

"In the past, people would refuse to be visited as they were afraid of being branded by the community that they were chronically ill or had HIV / AIDS-related illnesses. This was at the time when stigma was high."

Female caregiver, Ndola

"People have been sensitized in issues of stigma and people have come to understand that HIVI AIDS is just like any other disease, and can get treatment at anytime and have a fruitful life. ...Stigma is no longer an issue...people actually come to World Vision to ask. for services the moment they suspect that they are ill."

Program staff, Kalomo

\section{SO 2: HIV testing significantly higher among RAPIDS households}

At midterm, respondents from RAPIDS households were 36 percent more likely to ever have been tested for HIV.

- At endline, respondents from RAPIDS households were 24 percent more likely to ever have been tested for HIV.

During the development of the RAPIDS interventions, implementers introduced a new program component addressing access to HIV voluntary counseling and testing (VCT). RAPIDS began to introduce a new training component to HBC caregivers, equipping them to promote VCT for HIV among clients and their households. Increasingly, caregivers are being trained to provide counseling and administer HIV testing in the homes of their clients. 
There's acceptance because in the household, whatever comes out in terms of the action to be taken, it is something that is agreed upon by the couple. It is different when the mothers (we do routine testing for pregnant mothers) go alone; the man maybe tested alone at the workplace, and then it becomes difficult on how you open up communication when they get back together. So this one creates early involvement of either the male or the female, and then they bring in the other so that they make collective decisions and plan necessary follow-up.

Ministry Official, Lusaka

Household survey respondents reporting that they had ever been tested for HIV increased dramatically from midterm to endline among both males and females (data was not collected at baseline, prior to the introduction of this program goal). Female respondents reported a significant increase in having been tested in the prior six months (Table 6). Clinics remain the most popular service location for testing, while respondents seeking testing through a community/mobile center have dropped, even as the availability of these services have been increasing over time. During data interpretation meetings, RAPIDS Consortium partners suggested that the decrease in accessing testing through mobile services is a result of clients attempting to keep their access of VCT services private and anonymous, and choosing to go to a more distant counseling and testing centre rather than at the mobile VCT service visiting the community in which they work and live.

Table 6 Reported HIV testing among household survey respondents

\begin{tabular}{|c|c|c|c|c|}
\hline & \multicolumn{2}{|c|}{ Males } & \multicolumn{2}{|c|}{ Females } \\
\hline & $\begin{array}{c}2007 \\
\%\end{array}$ & $\begin{array}{c}2009 \\
\%\end{array}$ & $\begin{array}{c}2007 \\
\%\end{array}$ & $\begin{array}{c}2009 \\
\%\end{array}$ \\
\hline & $n=605$ & $n=695$ & $\mathrm{n}=816$ & $\mathrm{n}=1,010$ \\
\hline \multirow[t]{2}{*}{ Ever been tested for HIV? } & 24 & $44^{* *}$ & 31 & $58^{* *}$ \\
\hline & $\mathrm{n}=146$ & $\mathrm{n}=305$ & $n=252$ & $\mathrm{n}=581$ \\
\hline$\%$ tested in last 6 months, among those ever tested & 55 & 55 & 52 & $60^{*}$ \\
\hline \multicolumn{5}{|l|}{ Where did this test take place? } \\
\hline Clinic & 39 & 57 & 52 & 65 \\
\hline Hospital & 29 & 21 & 22 & 22 \\
\hline VCT centre & 5 & 7 & 14 & 5 \\
\hline Community/ mobile centre & 26 & 16 & 11 & 9 \\
\hline Home & 1 & 0 & 1 & 0 \\
\hline
\end{tabular}

${ }^{*} p \leq 0.05,{ }^{* *} p<0.01$ comparing midterm to endline

Logistic regression was used to determine the odds of a respondent from a RAPIDS household being tested for HIV versus a respondent from a non-RAPIDS household. The model controlled for sex of household head, respondent characteristics (age, marital status, education), and household composition 
(number of adults and children, if the household includes a child who has been orphaned or taken in, or an individual who is chronically ill). At midterm, respondents from RAPIDS households were 36 percent more likely to have ever been tested for HIV (OR 1.36 [95\% CI:1.03-1.81]; p > 0.031) than respondents from non-RAPIDS households. At endline, respondents from RAPIDS households were 24 percent more likely to ever have been tested for HIV (OR 1.24 [95\% CI:1.00-1.56]; p > 0.054).

\section{SO 1 and 2: Caregiver visits increased significantly}

At endline, 69 percent of households reported that caregivers had brought change.

During the study period, the coverage of OVC caregiver visits among eligible households between baseline and endline showed significant expansion, increasing from 7 to 17 percent overall (Table 3). However, population coverage is low overall, with high and increasing levels of vulnerability and unmet demand in the community.

Surveys measured the coverage of caregiver visits, including contact during the prior six months and during the prior week. The coverage of HBC caregiver visits showed a slight (but not statistically significant) increase from 12 to 15 percent of eligible households between baseline and endline. It is important to note that this change took place during a period of rapidly expanding access to antiretroviral treatment, which changed the dynamics of household eligibility and demand for RAPIDS services for many reasons, including improvements in clients' health and mobility. During the same period, among households who reported receiving caregiver visits to support OVC or chronically ill individuals over the prior six months, the mean number of reported visits during the preceding six months increased significantly from 2.3 visits at baseline to 10.9 visits at endline. Among those who had a caregiver visit, the households reporting having a caregiver visit during the past week increased significantly from 12 percent at baseline to 34 percent at endline $(p<0.01)$. Sixty-nine percent of respondents reported that the caregivers had brought changes to the household, a significant improvement from 53 percent at baseline $(\mathrm{p}<0.01)$.

In late 2006, RAPIDS, in conjunction with World Bicycle Relief, began providing bicycles to the $18,000+$ caregivers who work with the Consortium, in order to help them to reach clients spread across a wide geographical area. Among households receiving a visit from caregivers during the preceding six months, there was a 66 percent increase between baseline and endline among those who reported that the caregiver arrived by bicycle, correlating that bicycles played a significant role in caregivers overcoming transportation barriers to service delivery. Furthermore, during focus group interviews, caregivers testified that the use of bicycles had resulted in improved quality and duration of their caregiving visits.

"When I got the bicycle from RAPIDS, I found myself spending extra time with clients and getting to know them better - this is because I was making frequent visits."

Female caregiver, Kalomo 


\section{SO 1 and 2: Recipients reported positive experience of caregiver visits}

During qualitative research, RAPIDS clients and stakeholders listed some of the positive changes that were associated with the services of the RAPIDS program. Members of client households cited examples of how circumstances within their homes had changed for the better since a caregiver had started visiting them, including improved levels of activity among people who were chronically ill, and improved school attendance among children living in the household who had been orphaned.

"My granddaughter was not able to go to school, but through RAPIDS' help she is in school and will be completing her primary education this year. I am very thankful to RAPIDS."

"RAPIDS has belped the sick to get back to better health and also belped orphans to go to school."

RAPIDS clients, female, Kalomo

"The orphans are now able to go to school because of World Vision. Children were covering long distances to go to school but since the coming of RAPIDS, there has been some community schools that have been built nearer to the communities so that children can walk shorter distances to school."

Stakeholder, male, Kalomo

"Yes people appreciate when you bring them stuff so I'm sure the caregiver kits were helpful but it's the fact that you've got people in the community who go out there and see people in their bomes on a frequent basis and make people feel appreciated and welcome and still part of their communities when otherwise they may have been ostracized has a huge impact"

US AID official, Lusaka

Furthermore, testimony from clients and caregivers suggested strong, close and positive connections between caregivers and their clients, building warm and supportive relationships. This finding is in accordance with reports from RAPIDS monitoring systems, indicating that RAPIDS has found caregiver retention within the program to be high (approximately 97 percent).

"We feel good, because we see that after bathing the client who was dirty and he or she is looking fine, we feel good. Yes, this makes them feel happy too, and they even open up, they start sharing some of the problems they are facing."

Female caregiver, Mpika 
"Yes, I would recommend [RAPIDS services] to a friend, especially those that are sick and need encouragement in taking of medication and looking after one's life to live longer."

Male client, Kalomo

\section{SO 1 and 2: Caregivers cite need for additional supplies, training and support for themselves and clients}

Comments from caregivers indicate great commitment and dedication to their role and to meeting the needs of their clients. However, caregivers suggested that a lack of supplies affects the quality of the services that they provide. Caregivers requested greater attention from RAPIDS to regularly replenish their supplies-especially the contents of their caregiver kits-in order to enable them to provide a better service to their clients. Other requests for supplies that would help caregivers with an incentive to do a better job included something tangible to identify them as caregivers (ID cards, uniform, t-shirt), gear to help them to move around during the rainy season (umbrella, coat, boots), and bicycle spares. Some of these supplies had already been received by some caregivers in some sites, but coverage was patchy ${ }^{3}$.

"We take our kits for helping our friends [clients], but these are not enough. Some things just last for a single round. You can't even conduct psychosocial counseling — without medicine it is even embarrassing to start off."

Male caregiver, Kalomo

"I find it difficult because every time I go there I have to wash, draw water, sweep. They want soap and you find I don't have soap, so I find it difficult."

Female caregiver, Mpika

Caregivers indicated that they valued the training they had received from RAPIDS, and underscored the importance of training in psychosocial support. They requested ongoing and refresher training sessions to continue to improve the quality of the caregiving duties that they perform. However, by far the most requested training content was to provide skills in income generation for the post-RAPIDS future, for both caregivers and their clients.

${ }^{3}$ RAPIDS colleagues report that ID cards are currently being printed and will be distributed to all active caregivers. 
"The training was adequate at the time, but now we need training in how to run businesses so that we can impart this knowledge to our clients. This will belp them make a life for themselves when RAPIDS finally leaves this year." [Clapping.]

Female caregiver, Kalomo

[male] "This work of caregiving hinges more on psychosocial support, because we deal with troubled people psychologically. You talk to widows, orphans and many people with different problems, so psychosocial [support] is the pillar in the work of a caregiver."

[Mod: So, can you say that this training you had was adequate or not?] ....

[female] "It was adequate, that is why we are able to interact and talk to clients successfully."

Caregivers, Ndola

Caregivers continued to seek support, encouragement and appreciation in their role. They requested explicit recognition from RAPIDS that they are acting in a voluntary capacity and that they too come from the same vulnerable communities as their clients.

[Mod: "Do you receive any encouragement and supervision from [RAPIDS partner]?"]

"Sometimes they come with us during visitation to observe and also find out what problems our clients are facing."

Female caregiver, Ndola

\section{SO 1 and 2: Distribution of gifts-in-kind reflected program supplies more than client needs}

While clients appreciated the gifts-in-kind (GIK) that were distributed by RAPIDS, comments from caregivers and their clients suggest a mismatch between the goods received by clients and the supplies that they actually request from the program to meet their needs. Distribution of materials was supplydriven rather than demand-driven, reflecting the stocks of program supplies and the restrictions of donor policies. 
"They are trying to meet the real needs, but most of the time they give out what they have been sent and not what households need."

Female client, Kalomo

"They give us milk, sometimes they bring soap, T-shirt-but our cry is that us who are on medication, we need food. They bring toothbrushes, but what we need is food!"

Male client, Kalomo

\section{SO 1 and 2: Client selection for distribution of goods and services improving and addressing challenges}

Although RAPIDS client households reported appreciation for the gifts-in-kind and schooling support for children, there remained dissent about the procedures by which these kinds of support were distributed. At midterm, allegations of favoritism, nepotism, and theft during distribution were reported; i.e., caregivers keeping goods for themselves and their families or excluding someone that they have had a disagreement with. By endline, qualitative data subsequently appear to point towards a lessening of such complaints reported from within the communities.

Specifically, clients and caregivers more explicitly acknowledged the difficulties inherent in apportioning a limited amount of goods for distribution among a community with widespread levels of need. Despite limitations, the RAPIDS program appears to be reaching the people who are most in need of services, and better conceding its restrictions to those who are left out. It is commendable that RAPIDS Consortium partners have responded to the allegations of misallocation of goods since they were first documented, by implementing a community-level transparency program through the Community Care Coalitions (CCCs).

"The services are reaching some needy households, but the services are limited and cannot reach each and every person who is need. But yes, the services are reaching the neediest people in the community." [Agreement]

Female client, Kalomo

"The services provided by RAPIDS are helping, but they are not enough to go round to all the needy households. There are too many people in need and hence the RAPIDS people cannot manage to satisfy each person's needs. It is just difficult to please everyone."

Male client, Kalomo 
"The services being offered by World Vision are very good indeed. The only problem is the distribution - that is where there is a problem. That's where we are complaining. So when things come, they get other people and give, and the time they recruit them we don't even know."

Female client, Mpika

"We thank them for the services they bring to us, but...the people in front who are trusted with these things, they are the ones who confuse things, because what they do when some help comes, they first look at themselves and their relatives and friends."

Male client, Mpika

\section{SO 3: Unmarried youth respond to abstinence messages but need continued encouragement and reinforcement}

Between baseline and endline, communication of RAPIDS' messages about preventing HIV through abstinence have been reaching their target audience of unmarried youth aged 15-24. Youth from RAPIDS households report higher levels of exposure to the abstinence messages during the past six months than youth from non-RAPIDS households, especially among males (males 42 percent vs. 57 percent, $\mathrm{p}<0.024$; females 44 percent vs. 55 percent, $\mathrm{p}<0.099$ ) (Table 7). By endline, males from RAPIDS households were significantly more likely to report having attended an organized activity promoting abstinence (e.g., drama, singing, group discussion) than their non-RAPIDS counterparts (32 percent vs. 17 percent, $\mathrm{p}<0.011)$, while females showed little difference.

Youth opinions about the appropriateness of the abstinence messaging for their lifestyles show some variation. While survey data suggest that many youth perceive abstinence to be a beneficial message in their lives, qualitative research revealed that unmarried youth are frustrated by the limitations on the HIV prevention options shared with them, and that they would like further information about HIV prevention options beyond abstinence and being faithful. Responses from within the RAPIDS youth groups indicate that the messages are not always reaching their intended audience; for example, sometimes married youth who joined the group to learn livelihoods skills are being taught about abstinence.

"We are taught a lot but the information on HIV/AIDS is a bit outdated. The youth are hungry for better information so that we can make informed decisions."

Female youth, Kalomo 
"We learnt about abstinence-but most of us are married, so that issue of abstinence was irrelevant!" [Laughter]

Female youth, Mpikea

"Some of the things we are tanght on HIVIAIDS are a bit outdated. As youths, we are hungry for more information, and the trainers are failing to meet our demand for knowledge."

Female youth, Kalomo

Qualitative interviews also found that increasingly people, especially those in the metropolitan areas, do not necessarily share the religious values of the Consortium. Among youth, religion is not as much as a guiding factor as it is among elders. Youth are more likely to be concerned about the limiting the rights of an individual to do what they want, issues of sexuality, and equality.

"Youth of nowadays argue out rights and freedoms as opposed to religious ideals. Youth are not as religious as their parents, but more about rights and freedoms. The youth will not accept the religious announcements, preaching of abstinence."

Ministry Official, Lusaka

"Certain ideals may not be appreciated by the young people by the nature of them being young people. Like the issue of certain contraceptives. Don't use this (condoms) but at the same time we know that the youth are very active in this issue."

Ministry Official, Lusaka 


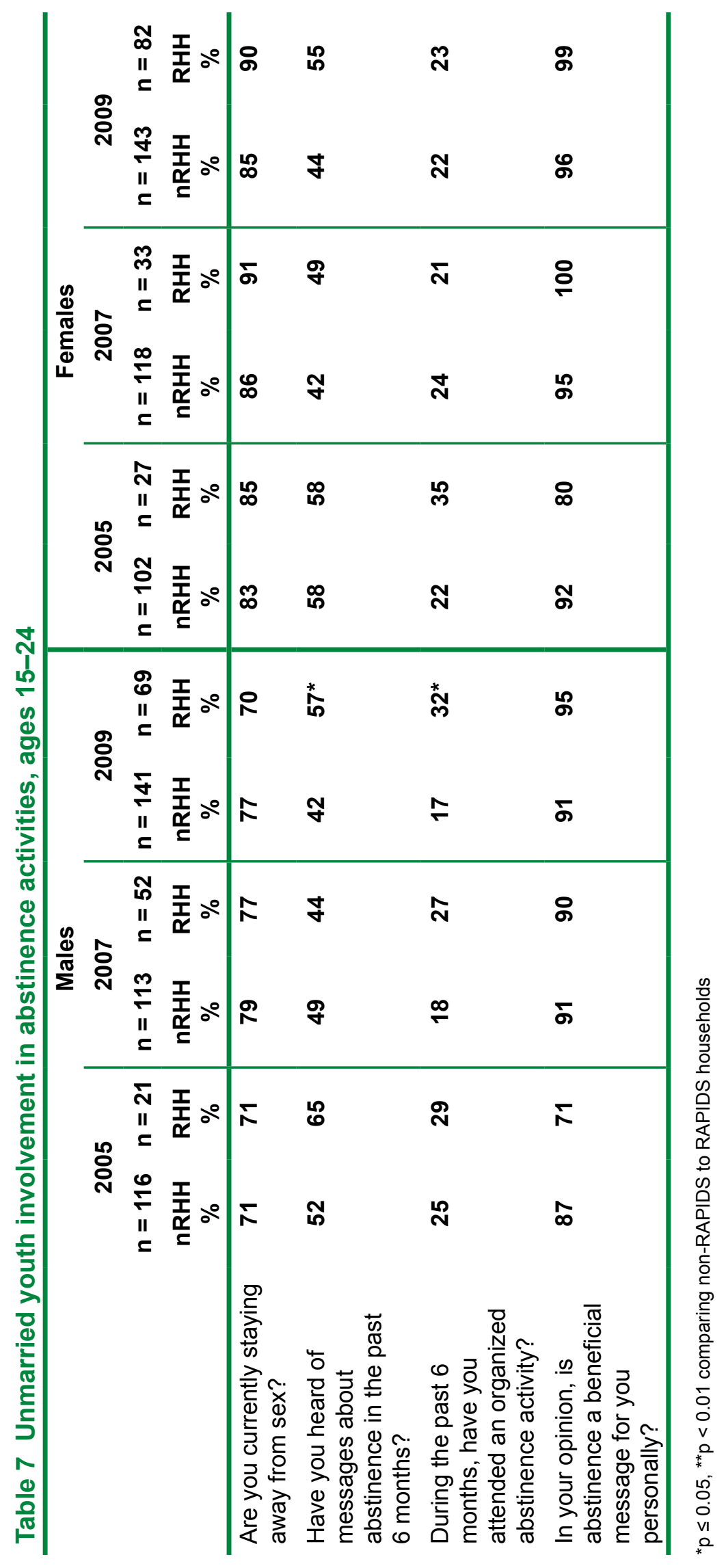




\section{SO 3: Secondary abstinence among female youth increased significantly over study period}

There was no statistically significant change over time among unmarried youth ages 15-24 who reported having ever had sex (Table 8). However, in interpreting this data, it is important to note the changing demographic profile of youth surveyed: youth surveyed at endline were significantly older (mean age 17.2 years) than youth surveyed at baseline (16.3 years) suggesting that older youth are continuing to delay their sexual debut (primary abstinence), as recommended by the RAPIDS intervention messages. Consistently throughout the entire study period, when asked for how long they plan to stay away from sex, approximately half of youth abstaining reported they will stay away from sex until marriage and approximately another quarter reported they will stay away from sex until they complete their education (data not shown).

Female youths aged 15-24 who were previously sexually active are reporting less sexual activity recently, which may be related to the abstinence message that they are receiving through RAPIDS. Data show that Zambian youth are hearing abstinence messages and are open to receiving multiple messages about different HIV prevention methods. However, against a backdrop in which youth are receiving multiple and often conflicting messages, youth are seeking more information from a trusted source. No significant differences were observed when disaggregating by RAPIDS households (data not shown), reflecting the community-wide nature of the messaging.

Table 8 Primary and secondary abstinence among unmarried youth ages 15-24

\begin{tabular}{lcccccc}
\hline & \multicolumn{3}{c}{ Males } & \multicolumn{3}{c}{ Females } \\
& $\mathbf{2 0 0 5}$ & $\mathbf{2 0 0 7}$ & $\mathbf{2 0 0 9}$ & $\mathbf{2 0 0 5}$ & $\mathbf{2 0 0 7}$ & $\mathbf{2 0 0 9}$ \\
\% answering yes & $\mathrm{n}=\mathbf{2 2 0}$ & $\mathrm{n}=\mathbf{1 7 5}$ & $\mathrm{n}=\mathbf{2 2 5}$ & $\mathrm{n}=\mathbf{2 1 9}$ & $\mathrm{n}=\mathbf{1 7 1}$ & $\mathrm{n}=\mathbf{2 5 8}$ \\
& $\%$ & $\%$ & $\%$ & $\%$ & $\%$ & $\%$ \\
\hline Have you ever had sex? & $\mathbf{5 7}$ & $\mathbf{6 1}$ & $\mathbf{5 3}$ & $\mathbf{4 0}$ & $\mathbf{4 2}$ & $\mathbf{4 6}$ \\
& $\mathrm{n}=65$ & $\mathrm{n}=105$ & $\mathrm{n}=117$ & $\mathrm{n}=44$ & $\mathrm{n}=66$ & $\mathrm{n}=107$ \\
$\begin{array}{l}\text { Of those who have ever had } \\
\text { sex... have you had sex }\end{array}$ & $\mathbf{4 2}$ & $\mathbf{3 6}$ & $\mathbf{3 9}$ & $\mathbf{3 6}$ & $\mathbf{1 8}$ & $\mathbf{2 2}$ \\
within the last 3 months? & & & & & & \\
\hline
\end{tabular}

${ }^{*} p \leq 0.05,{ }^{* *} p<0.01$ comparing baseline to endline only

\section{SO 3: Youth emphasize preference for income generating activities over life skills training}

At endline, youths living in RAPIDS households were significantly more likely to have participated in income generating activities. 
Among the male youth covered in the household survey, involvement in RAPIDS livelihoods activities (facilitation, leadership and business management), vocational skills training (tailoring, knitting, carpentry and catering) and micro- enterprise development, increased significantly during the evaluation period, from 20 percent at baseline to 38 percent at endline. However, participation of females in livelihoods activities appeared to lag behind, remaining stable at 15-17 percent when compared to their male peers. Both male and female youth living in households who reported receiving RAPIDS services in the past six months showed a much higher rate of reporting that they had participated in any income-generating activities (Table 9); females significantly so (24 percent vs. 11 percent, $\mathrm{p}<0.000)$. This is a noteworthy finding as RAPIDS Consortium partners commented during data interpretation meetings that there have been few resources available for income-generating activities. Community leaders and RAPIDS program staff have called for renewed attention to strengthening income-generating projects and livelihoods activities for youth.

"The youth get discouraged when we don't meet their demands for livelihood introduction into the trainings — most of the youth have stopped attending meetings."

ToT, Ndola

"We have not been taught any livelihood services - that component has not started yet. We were told by our trainers that livelihood training would begin soon, but still there is nothing bappening — we have only learnt about life-skills."

Female youths, Kalomo

"My own personal feeling is that the livelihood sections had the least accomplishments... it's not clear to me that it was a demand driven approach of where is there an employment gap and how do we fill that gap with people who are rebounding from HIV ... How do you plug them into a real gap in the employment sector other than just saying we're going to train people to make bricks or teach them how to sew? So that is where I've had the biggest questions did we adequately tie things into where the demand was."

USAID official, Lusaka

Discussion among youth indicated that there is great demand for skills training for youth in all aspects of business management for income-generating activities, indicating the importance of teaching self reliance. Training in specific and marketable skills (e.g., tailoring, mechanics, and carpentry) is highly sought after. Furthermore, youth seek start-up capital to enable them to set up business ventures such as gardening and chicken-rearing. In addition, an existing youth business venture set up by a RAPIDS youth livelihoods group called for more support from RAPIDS to help them to address major obstacles including unpaid bills, lack of inputs, and lack of training. 
"We could strengthen on the area of income generation component; we need to find something that will have good returns for them [youth], to make the youth stick around longer. ...We need to strengthen the livelihood component."

Program staff, Kalomo

(female) "The services provided by RAPIDS are limited—just teaching us lifeskills is not enough. We need livelihoods [training], where [we] can earn some money to support our families and pay school fees.”...

(male) "What we need is money to start some business ventures, and we need to be trained in income-generating activities like tailoring, gardening and carpentry. We need training in these skills so that we can have basic knowledge to help us start from somewhere."

Youths, Mpika

"It takes much more hands on to determine if person $X$ is going to be much more of a follower and given direction they will do great while person $Y$, is much more entrepreneurial and they only need a little bit of direction and some skills and they will take off, but they'll need the others to be their employees."

USAID official, Lusaka

While further discussions with key informants indicate that there are questions whether the skills taught will do more than allow the participants to fill the employment gap or allow them to start and grow a business; spending time with youth and teaching them skills in addition to providing HIV and life messages is beneficial and of value. 


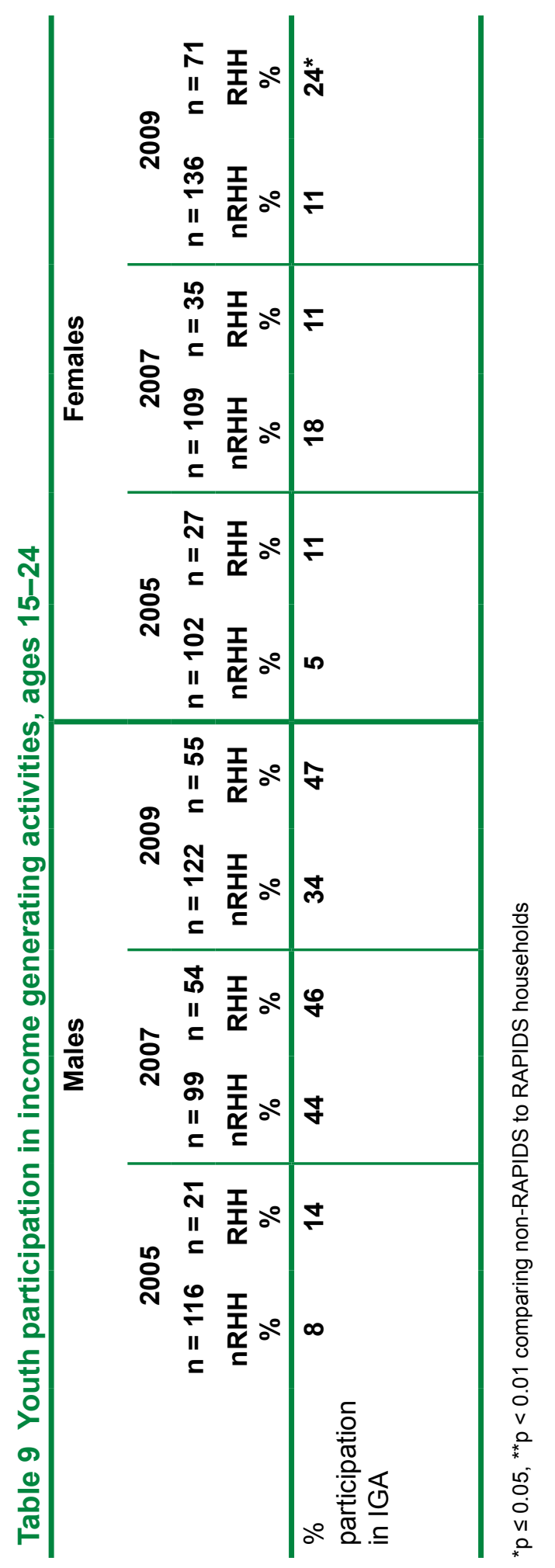

RAPIDS Evaluation Final Report 2005-2009 Key Findings घ 27 


\section{SO 4: RAPIDS households demonstrated better food security, but demand remains high}

- At baseline, RAPIDS households were 51 percent more likely to have had 2+ meals the previous day.

- At midline, RAPIDS households were 92 percent more likely to have had 2+ meals the previous day.

- At endline, RAPIDS households were 27 percent more likely to have had $2+$ meals the previous day.

Initially, a component of RAPIDS service delivery-food distribution — was halted in accordance with PEPFAR policy. By 2006, PEPFAR guidance indicated that "Emergency Plan funds may pay for the procurement of food only as a last resort," and that only clinically malnourished children and adults and pregnant lactating women are eligible for food support ${ }^{4}$. Overall, these findings show the potential of a food distribution program to have had significant effects in reaching households while it was supported by donor policy.

Among households supporting someone who is chronically ill or a child who had been orphaned or taken in, coverage of RAPIDS food support services such as beans, maize, cooking oil or kapenta, increased from 10 percent to 13 percent overall (Table 3). During the same period, data show that the demand for food support was consistently high — up to 90 percent of households surveyed requested food support at endline.

Logistic regression was used to examine household food security, based upon an indicator of the number of meals that household members ate the previous day. The model controlled for sex of household head, respondent characteristics (age, marital status, education), household composition (number of adults and children, if the household includes a child who has been orphaned or taken in, or an individual who is chronically ill) and household mode of food production (if the household mainly produced its food, bought its food, or both). At baseline, RAPIDS households were already 51 percent more likely than non-RAPIDS households to have had 2+ meals the previous day (OR 1.51 [95\% CI: 0.97-2.33]; $\mathrm{p}>0.067$ ), reflecting the fact that RAPIDS partners were already engaged in food distribution prior to the initiation of RAPIDS activities. By midterm, the food security advantage of RAPIDS households had increased to 92 percent over non-RAPIDS households (OR 1.92 [95\% CI:1.23-2.98]; $\mathrm{p}>0.004)$. At endline, RAPIDS households were 27 percent more likely to have had $2+$ meals the previous day (OR 1.27 [95\% CI;0.84-1.44]; $\mathrm{p}>0.502$ ) but this was no longer statistically significant different from the households who had not received RAPIDS services. (It is possible that some of the changes may have been associated with seasonal factors.) These changes in the food security advantage of RAPIDS households appear to reflect changes in the donor policy on food support during the period of RAPIDS program implementation.

\footnotetext{
${ }^{4}$ PEPFAR Policy Guidance on the Use of Emergency Plan Funds to Address Food and Nutrition Needs, September 2006, http://www.pepfar.gov/guidance/77980.htm.
} 
During focus group discussions, clients and caregivers especially emphasized the crucial role of RAPIDS in addressing poverty and distributing food. Meeting clients' nutritional needs is especially important for those who are on antiretroviral treatment (including high-energy protein supplements / HEPS).

"Those days, they used to give us HEPS, but that is no more, so we are suffering-we need food."

Male client, Kalomo

"We stopped providing food supplements to clients, and hence most of our clients have been asking for food. The lack of a food component has made a number of our clients abscond from taking their ARVs. This is dangerous for their health and retrogressive to the program."

Program staff, Ndola

\section{Other important findings from the evaluation}

Findings from this evaluation of the RAPIDS program illustrate that over the study period of 20052009 , there have been improvements in many areas addressed by RAPIDS strategic objectives as discussed above but the impact of RAPIDS was not limited to those areas alone. Other interesting findings were detected during that time and are discussed below.

\section{RAPIDS explores knowledge on alcohol risks and gender-based violence}

During endline data collection, the RAPIDS Consortium partners requested the introduction of a new survey module addressing the risks of alcohol and gender-based violence in increasing vulnerability to HIV transmission, reflecting evolving program concerns. Survey respondents were asked to answer questions on their knowledge of the effects of alcohol on the body, sexual performance, pregnancy, and its use in relation to HIV (Table 10). This data is intended to inform new RAPIDS program activities, including pilot programs to address youth awareness of drugs and alcohol in Chongwe and Mazabuka. A majority of male and female community members appeared to already be aware of some of the risks of alcohol consumption. Male and female respondents were least likely to be aware of alcohol risks during pregnancy. 
Table 10 Knowledge of the effects of alcohol by household type"



"Endline data only

Data collected during the endline survey indicates that female respondents believe gender-based violence is more of a problem in their community than male respondents (74 percent vs. 64 percent, $\mathrm{p}$ $<0.000$ ), while both sexes agree that spousal abuse is the most common type of violence (Table 11). There was no difference between sexes when split by RAPIDS service indicator. However, households who received RAPIDS services in the prior six months were significantly more likely to have heard a caregiver talk about rape or defilement than those households that had not received services in the previous six months (Table 12).

Table 11 Gender-based violence

\begin{tabular}{lcc}
\hline & $\begin{array}{c}\text { Male } \\
n=698 \\
\%\end{array}$ & $\begin{array}{c}\text { Female } \\
\mathbf{n}=1,012 \\
\%\end{array}$ \\
\hline $\begin{array}{l}\text { Do you think gender-based violence is a problem in your } \\
\text { community? (\% yes) }\end{array}$ & 64 & $74^{* *}$ \\
$\begin{array}{l}\text { In your opinion, which type of gender-based violence is most } \\
\text { common: }\end{array}$ & & \\
$\quad$ Spousal abuse & 48 & 50 \\
Rape & 5 & 5 \\
Defilement & 10 & 13 \\
Property grabbing & 13 & 15 \\
Don't know & 18 & 13 \\
\hline
\end{tabular}

${ }^{*} p \leq 0.05,{ }^{* *} p<0.01$ comparing males to females, endline only 


\begin{tabular}{|c|c|c|c|c|}
\hline & \multicolumn{2}{|c|}{ Male } & \multicolumn{2}{|c|}{ Female } \\
\hline & $n=457$ & $n=241$ & $n=731$ & $\mathrm{n}=\mathbf{2 8 1}$ \\
\hline & $\underset{\%}{\mathrm{nRHH}}$ & $\underset{\%}{\mathrm{RHH}}$ & $\underset{\%}{\mathrm{nRHH}}$ & $\underset{\%}{\mathrm{RHH}}$ \\
\hline $\begin{array}{l}\text { Have you ever heard a caregiver talk about rape or } \\
\text { defilement? } \% \text { yes }\end{array}$ & 28 & $50^{* *}$ & 29 & $43^{* *}$ \\
\hline \multicolumn{5}{|l|}{$\begin{array}{l}\text { If someone needed medical care after rape or } \\
\text { defilement, where would they go? }\end{array}$} \\
\hline Traditional healer & 1 & 0 & 0 & 0 \\
\hline Health centre & 46 & 58 & 41 & 56 \\
\hline Hospital & 50 & 40 & 57 & 41 \\
\hline $\begin{array}{l}\text { Medicines are available to prevent pregnancy after } \\
\text { rape. (\% true) }\end{array}$ & 44 & 40 & 38 & 38 \\
\hline $\begin{array}{l}\text { Medicines are available to prevent the transmission } \\
\text { HIV after rape. (\% true) }\end{array}$ & 15 & 16 & 21 & 26 \\
\hline
\end{tabular}

${ }^{*} p \leq 0.05,{ }^{* *} p<0.01$ comparing non-RAPIDS to RAPIDS households, endline only

\section{Communication and coordination within and beyond the RAPIDS Consortium has proven to be complex}

The task of coordinating between RAPIDS Consortium partners and with external groups at all levels from national headquarters to the field sites is without question an extremely difficult one. RAPIDS partners have actively engaged in internal and external communication activities in order to work together to achieve program goals. For example, RAPIDS convened cross-agency technical working groups and coordination meetings, and shared information and engaged with Government Ministries and the District AIDS Taskforces. Nonetheless, discussion among RAPIDS staff and local stakeholders indicated a need for even wider information-sharing within and beyond the RAPIDS Consortium. Continued cooperation and communication is needed between Consortium partners in order to allocate resources efficiently and effectively_-for example, to avoid double-counting and duplication of services, to avoid potential clients being omitted from the program, and to better share resources. Staff and stakeholders requested that results emerging from the RAPIDS impact assessment be shared throughout the Consortium, so that the findings can be directly addressed.

"We are thankful to RAPIDS for all the work done, but one complaint is that we hardly ever meet with them in DATF [District AIDS Task Force] in order for us to know what activities they are planning. When RAPIDS started reports of their activities would be presented to us to keep us in the know, but these days we are only meeting with Salvation Army and World Vision."

Stakeholder, Kalomo 
"The question that I would really want to pose is that, time and again, the impact assessments have been done, but the challenge we have had is the feedback. You find that even where you have gaps, but when you don't have the feedback. from the people that did that, you find that you will not be able to improve, and my request is to have the feedback so that we can re-strategize and bridge the gaps, if any."

Program staff, Ndola

"We work together, and as the Area Development Committee, they all keep us posted, but I think RAPIDS is not working closely with the district institutions. ...It is important for $\mathrm{RAPIDS}$ to report back to community stakeholders on how well and bad the program is running so that we know where we are-we need each other."

Stakeholder, Ndola

"RAPIDS has done a good job at motivating communities, have done a good job at bringing a consortium approach in two things; getting themselves together and coordinating themselves, if there was internal bickering we didn't usually hear it so in terms on how they were able to operate as a consortia they seemed to be fairly successful. And that is certainly positive and they provided better care than what was there and better range of services than was ever been there before."

USAID official, Lusaka

\section{RAPIDS strikes a balance between coverage and quality}

The services provided by the RAPIDS Consortium are very much in demand, and there remains much unmet demand within the community. Service providers at various levels report that they have been facing a trade-off between the competing values of expanding service coverage to eligible households not yet reached and improving service quality to existing household recipients. While implementers remain under pressure to meet service targets, they are committed to not sacrificing the quality of existing services. Intervention components that have helped to maintain and even improve service quality have included the distribution of bicycles to caregivers. Also crucial to providing high-quality services is ongoing training and support to RAPIDS volunteer caregivers, including keeping their supplies replenished and providing incentives to make sure that they feel valued and appreciated by the program and contribute to high volunteer retention rates.

\section{RAPIDS readily responds to evaluation findings in a changing environment}

The period through which the RAPIDS interventions have been implemented has been a time of dramatic change for families and communities in Zambia. In 2004 the major focus of HBC was visiting 
the households to assist with the bedridden. Since 2006, HBC caregivers have found it harder to find HIV positive clients at home as they benefit from the scale up of ART and are now seeking assistance in rejoining the workforce. Still other households have members who do not recover and the remaining members require support associated with OVCs. Evidence shows that the RAPIDS Consortium has demonstrated flexibility in responding to the new and changing circumstances adapting care and support package, including expanding HBC caregiver training to include ART adherence support and pain management. Due to practical and ethical obstacles preventing the use of randomization and a control group, the study design cannot definitively attribute community changes in the core indicators to the RAPIDS program. However, the cross-sectional logistic regression models provide evidence of positive improvements in educational status, food security, and accessing HIV tests that are associated with the RAPIDS programs.

RAPIDS service providers are to be commended for their responsiveness to emerging evaluation findings during the intervention implementation period. For example, baseline findings in 2005 indicated that household members were frequently confused between the roles of OVC and HBC caregivers, and suggested that there may have been some duplication between their responsibilities. By the midterm survey in 2007, RAPIDS had begun to roll out the new "household approach," in which individual caregivers aim to respond to the combined needs of all household members. RAPIDS had also responded to midterm findings recommending the need for greater appreciation of volunteer caregivers by holding a “Caregivers' Day” in November 2008.

Another example of RAPIDS' responsiveness to evaluation findings is evidenced by improvements in the client selection process: midterm results documented overall client dissatisfaction with the process, including allegations of misappropriation of goods within the program. By endline, qualitative data appear to show a lessening of such accusations and dissatisfaction, and increasing understanding of the program constraints, reflecting greater efforts among program management to address transparency and accountability through the development of community-based mechanisms. RAPIDS has also been responsive to donor priorities and addressing emergent needs in the community, by introducing new intervention components including expanding access to HIV testing and addressing the risks of alcohol consumption and gender-based violence within the framework of HIV prevention. Based on data indicating that a number of youth group members were married, a faithfulness module was introduced.

\section{RAPIDS structure as a Consortium, extensive caregiver network, and distribution systems are assets to Zambia}

The Consortium covers 52 districts, and is nearly nationwide in scope. At the onset of the program, CRS provided the majority of the HBC, Africare the majority of youth and livelihoods instruction and training, and WVI serviced most of the OVC. Over a short time resources were allocated to each consortium partner so that each could scale up similar services in the areas where they focused on service delivery. 


\section{RAPIDS must prepare for increasing demand for more sophisticated palliative care in the near future}

As the HIV-positive population retains healthy living, more resources will have to be allocated to taking care of the different needs of this new chronically ill population. Qualitative interviews with key informants suggested that along with the four components of palliative care (physical, social, spiritual, and psychosocial support), physiotherapy will increasingly play a key role. The current two-week training for palliative caregivers includes one week of physiotherapy which may not be enough to train caregivers in even the very basics of physiotherapy.

\section{Placing of RAPIDS technical advisors within Zambian ministries beneficial for all}

By and large, all key informants agreed that the placement of the technical advisors were integral in developing policy for children's rights, gender-based violence and OVCs and keeping the Ministries appraised and involved with RAPIDS programs.

"We worked tirelessly with this lady who was stationed here, the RAPIDS officer. Then also from this being a policy we also worked together to develop a national plan of action to insure that the implementation of the policy was more focused, we have this national development plan and in the past we never had a chapter for children but we forced and convinced the national planning office that issues of children and OVC should appear in the national plan. We worked with RAPIDS on this."

Ministry official, Lusaka

\section{RAPIDS ability to acquire GIK on a large, country wide scale was an asset to the program but sustainability is in question}

Key informants all mentioned the very large amount of GIKs that RAPIDS distributed over the life of the program. In one example, the RAPIDS consortium acquired a total of 2 million tablets for the treatment of worms and bilharzias as well as vitamin A supplements for the School Health and Nutrition Program, run by the Ministry of Health. Other key informants mentioned learning materials, shoes, and bikes all in very large scale. When asked what the dollar figure is on the GIK over the life of the project, it nears 130 million USD.

While there was no one that did not praise the RAPIDS consortium for brining in these massive donations, USG officials brought up how difficult it was to disaggregate and then measure the impact that was a result of GIKs versus that from the 57 million USD provided by the USG. 
"What you can do with that dollar is very different than what you can do with a pair of shoes. When looking at the caregivers, there is no doubt in my mind that the shoes, hats, the things they received were very well valued and probably better than giving then a bundred dollars because it last longer and goes further. So at the adult level it probably, and as the caregiver which is more of an employee versus the recipient, I think there are questions there concerning the value of what was provided. We don't have good measures on how these gifts and services achieve program goals.”

USAID, Lusaka 


\section{SUSTAINABILITY}

The evaluation endline data were collected in March-April 2009, several months away from the anticipated close-out date of RAPIDS intervention funding. Key informant interviews were conducted in December 2009. As the end date for RAPIDS program activities approaches, clients are aware that the program is coming to an end and unsure about the future. Program staff report that they have engaged in capacity-building exercises with local CBOs to prepare for RAPIDS' exit. Some caregivers indicate that they are committed to continuing their visits but are worried about how inputs will be funded, while others are hoping that they can be taken on by another program to continue their work. Staff and stakeholders claim that programs that were established prior to RAPIDS will still continue; however the distribution of material goods will be the hardest to maintain without the GIK pipeline that RAPIDS created. Anticipating the end of RAPIDS, there is great demand from community members and stakeholders for training in business skills and income-generation activities. Such activities are sought both for individual clients to become self-sufficient, and also for caregivers to earn money to purchase the supplies needed to maintain their services after RAPIDS support ends. Suggestions include links to low-interest loan schemes, skills training (carpentry, tailoring, marketing, business management), and investment (of capital, livestock) for future livelihoods ventures.

"The services will not continue as people have not been empowered with income-generating activities. Even the caregivers will completely stop their visitations as the will have nothing to offer their clients."

Female client, Kalomo

"We will continue. It doesn't mean that because the program is gone, therefore we should stop visiting the sick. No, we have to continue... but it won't be the same, because the assistance we take to our clients comes from RAPIDS, because we don't have the muscle to give the assistance that we have been given through $\mathrm{R} A P I D S$. Therefore unless they leave us with a strong base, we cannot do as we have been."

Female caregiver, Mpika

"I have been a volunteer for a long time and there is no way I can stop making visitations — the people we serve in the communities know us and they will be still coming to us for belp, so I cannot stop."

"As much as I would like to continue, I feel it will be more difficult to continue since we have nothing to give them except moral support and counseling — all that to a patient would be lip service."

Female caregivers, $N$ dola 
"We have no future plans. If RAPIDS was to go today, then the program would suffer a lot. If you look at $A R V$ s, people are taking — they help the immune system and there is no cure. People in this community are still getting infected by the virus therefore when RAPIDS leaves, it means that people will suffer and there will be many deaths." [Agreement]

"What I can say, I think that the support groups will continue and people will be advising each other. Our clients will continue meeting in this manner. I only wish for RAPIDS to train caregivers in income-generating activities, so that we can impart those skills to the clients."

\section{Female caregivers, Ndola}

Key informants as a group all agreed that what has been created is not sustainable. The services provided by the RAPIDS Consortium are very much in demand, and there remains a lack of financial ownership of the Zambian government, the one most important factor of organizational ownership. Therefore, future success hinges upon the Zambian government eventually assuming responsibility, both physically and financially, of the services provided by RAPIDS. Furthermore, nearly all the GIK was from US corporate sources, and there has been very little corresponding build up of corporate giving in Zambia. This will greatly reduce material goods destined for the participants and for supporting and encouraging the caregivers and must be replaced.

"In the second phase, if all things go well, we should also demand Zambian government contribution to this. We have given her an office but we don't pay her anything. And it can. If you buy in like that it is more sustainable. It will remain a part of their treasury process. Zambia government should chip in. it will be beneficial to get Zambia involved."

Ministry Official, Lusaka

"I'm hoping that the sustainability under the consortium was not the second phase of RAPIDS but in themselves being able to continue with the good works which they have done. This intervention is not only about a program which is coming to a level that is being evaluated it is about life. The RAPIDS consortium and these objectives and those objectives have become part of people's lives."

Ministry Official, Lusaka 


\section{RECOMMENDATIONS}

Despite the difficult economic and health environment of Zambia where 81 percent of people live on less than 2 USD per $\mathrm{day}^{5}$, RAPIDS is a success, especially in caring for OVCs and for economically strengthening households made vulnerable by HIV/AIDs. While the current program has brought a great many benefits to Zambia the next phase of the program - while continuing with the successes of the first five years-must evolve to fit the future landscape of needs demanded by households living with HIV. This evaluation study has indicated the following recommendations to the RAPIDS Consortium on how to continue to improve the implementation of programs addressing the circumstances of families rendered vulnerable to HIV in high-prevalence settings.

\section{Strategic objective 1: Improve quality of life of orphans and vulnerable children and their households}

The RAPIDS Consortium successfully delivered and continually expanded household services to orphans and vulnerable children. Quantitative data and qualitative feedback both indicate that increasing caregiver frequency and length of visits has a very positive effect on the household's member's quality of life. This is in line with the recommendations from past evaluations to continue refining the household support model to service delivery. Furthermore, psychosocial support from caregivers as well as gifts in kind associated with the schooling requirements were very successful in raising the quality of life of OVCs via school attendance. The RAPIDS Consortium should consider continuing to spend effort acquiring school items that are needed by OVCs.

\section{Strategic objective 2: Improve quality of life of people living with HIVIAIDS}

The RAPIDS Consortium's caregiving services to people who are chronically ill must continue to address the changing needs of people living with HIV and AIDS as the availability of ART rolls out in Zambia. Continual access to counseling and testing services, especially offered at home simultaneously to the couple, remains important as a first step towards destigmatization and accessing treatment. RAPIDS should continue to address the caregiver role in adherence for PLHAs including monitoring client intake of ARVs and proper diet and exercise. Reliable sources of nutritional support, education and guidance are especially important for maintaining favorable outcomes among the increasing number of HBC clients on ART, due to the complex interactions between drug and food. While RAPIDS has been very successful increasing the frequency of caregiver visits, it can only be a benefit to continue to find ways to increase caregivers' length and frequency of visits. As a result of a successful caregiver program and the rehabilitation of the household, RAPIDS must prepare for

\footnotetext{
${ }^{5}$ Human Development Report: Overcoming barriers: Human mobility and development, United Nations Development Programme, 2009, Hampshire, England and New York.
} 
an increase in demand for palliative care, especially physical therapy, as clients live longer and develop later stages of the chronic symptoms of HIV/AIDs. At the community level, IEC activities focusing on addressing stigma and discriminating behaviors are still relevant. Finally, as service coverage and responsibilities continue to expand in size and scope, RAPIDS needs to develop a system to integrate their services within the Zambian health system.

\section{Strategic objective 3: Improve livelihoods for vulnerable youth}

The RAPIDS Consortium uses to its advantage the favorable disposition of youth to lifeskills training and abstinence messages to further reinforcing activities. RAPIDS livelihoods training appears appreciated by participants, but with limited capital and business opportunities, youth continue to face barriers in employing their new skills. The RAPIDS Consortium should explore creative new ways to create opportunities for youth to utilize their skills, including access to capital and experienced business leaders. Advanced vocational training to top graduates could be a way to seed business leaders in the communities. Young women are not accessing livelihoods training opportunities as well as their male counterparts, indicating a need for the RAPIDS Consortium to revisit programs activities in relation to the needs of females and their possible employment opportunities. Comments from key informants suggest that it was not clear how RAPIDs lifeskills training and income generating programs were being tailored to prepare the participants for current employment opportunities. Research into future economic growth trends could lay the groundwork for more effective livelihood programs. Finally, the RAPIDS consortium should continue to use lifeskills and livelihood training venues to reinforce HIV/ AIDS and other relevant messages to the attending youth. Finally, questions concerning alcohol and gender based violence indicated that alcohol related risks are well known and the resultant behaviors are witnessed and are a concern in the communities. RAPIDS should continue with plans to integrate alcohol awareness and gender based violence IEC in to the household model.

\section{Strategic objective 4: Strengthen resilience of households made vulnerable by HIVIAIDS}

With the continued vulnerability of female-headed households indicated through asset ownership and food security, RAPIDS Consortium partners are urged to maintain attention to programming that will provide particular support to female-headed households and households who lack healthy adult caregivers. The role of food support and supplementary food interventions is especially important to meet the nutritional requirements of people on ART. Caregivers should have additional training on how best to advise their clients on nutritional intake. More focused IGA activities, increasing caregiver visits, especially in households who are missing one or more health adult caregiver are crucial to the households' success. 


\section{Other program recommendations}

\section{Continual transparency and accountability in eligibility criteria and flow of goods and services}

To build and maintain trust and confidence, it is critical for programs to promote transparency and accountability, in order that all community members understand eligibility criteria and the flow of goods and services. Further, program managers must take care to ensure that the goods and services being delivered match those most needed by the community, and should pay particular attention to food security, livelihood training, and the types of goods distributed. Continuing attention to transparency and accountability in client selection and service delivery must also be maintained.

\section{Build a strategy to sustain the caregiver network}

The scope of RAPIDS volunteer caregiver network is unparalleled. Ongoing training and recognition provides caregivers with support critical for recruitment and retention. Caregiving supplies and other materials are a further source of crucial incentives to caregivers. The follow-on for RAPIDS will most likely require that the new program inherit the caregivers since they have already been trained. RAPIDS needs to ensure that this can happen.

\section{Fund a broader evaluation plan}

Evaluations of complex integrated interventions can be conducted to derive practical lessons for program implementers and funders but adequate levels of funding are necessary. Evaluating only the recipients of services is crucial but does not capture the complete picture. It is important to examine more closely the impact the program had on the caregivers over time, process and procedures used to implement services and deliver GIKs, and to maintain operations research to continuously provide feedback to improve the processes and cost-effectiveness of the program. The high reliance on selfreported behavior should be reconsidered as it is can lead to biased results. Triangulation of behaviors through observations and biomarkers should be considered. Future evaluations should have regularly scheduled contact between the evaluators and key informants and possibly imbed an evaluator within the programs monitoring and evaluation team for periods of time. Finally, to further remove the evaluation from influence by the program, funding should come from a completely separate source.

\section{Plans for sustainability and long term exit strategy must be emphasized}

Buy-in from the Zambia government, physically and financially, should be a necessary part of next phase of the project. One possible way is to require them to match contributing funds for the technical advisors posted to the ministry. Another could be to use the GRZ supply chain to move goods as long as it comes with associated safe-guards and accountability. 


\section{Building a strategy for communications and sustainability}

While the Consortium model has brought undoubted advantages to the implementation of the RAPIDS program interventions, evaluation study findings show a need for renewed attention to communication and cooperation within and beyond the RAPIDS Consortium, so as to enhance program efficiency and effectiveness. Service providers, volunteers and clients continue to seek strategies for sustainability and grappling with a smooth exit strategy that will not jeopardize existing clients. As part of a process of continuous attention to quality throughout the activities of the Consortium, there is a need for RAPIDS to provide feedback to stakeholders, community members and program staff at all levels who have participated in the assessment activities.

Finally, this evaluation of the RAPIDS program has demonstrated that the implementation of a large-scale complex integrated intervention can make significant progress towards addressing the circumstances of families and communities affected by HIV in a high-prevalence area. This study has indicated a number of important practical lessons relevant for the management of interventions focusing on the care and support of families affected by HIV in Zambia and beyond. It has also demonstrated the importance of sound evaluation for documenting processes and outcomes associated with a programmatic intervention, in order to inform donor priorities. The evaluation benefited from the introduction of hand-held devices for used for survey fieldwork which increased the efficiency and quality of data collection, pioneered electronic data capture in Zambia, and built capacity among Zambian colleagues. The methodological limitations of this evaluation study indicate new possibilities for exploring the effects of integrated approaches to development like RAPIDS, including tracking client households longitudinally, establishing comparison groups, estimating cost-effectiveness, and exploring how the lives of caregivers are affected by their duties. Continued research into evaluating other combinations of interventions to address the needs of vulnerable families living in high HIV prevalence areas remains crucial to informing donor spending. 


\section{ACKNOWLEDGEMENTS}

To the people of Zambia, if not for their magnitude of spirit for volunteerism, this program would not have been.

"The problem of HIVIAIDS really devastated a lot of people, the people felt the future is so bleak, because when people were saying that there is no medicine for such a thing and when you see it getting closer to you that meant that people were getting more and more hopeless now with the consortium and RAPIDS with their many interventions, children back into school, adults accessing medical facilities, you see the esteem or the pride of the community being rebuilt."

Ministry official

The researchers are grateful to the community leaders and community members in Chongwe, Kalomo, Mazabuka, Mpika, Ndola and Petauke for taking part in the household surveys, focus group discussions and in-depth interviews. Thanks also to the caregivers, local stakeholders and key informants.

The guidance of RAPIDS Consortium staff and partners in Lusaka and throughout the six districts was crucial to the development of this activity. We are grateful to all our RAPIDS colleagues at PMU and in the districts, who have provided us with access to programmatic information and insights. Thanks to RAPIDS colleagues for their feedback and suggestions on earlier drafts.

Population Council was contracted by Africare on behalf of the RAPIDS Consortium to conduct an impact assessment of the RAPIDS programmatic interventions.

Population Council's local research partner in Zambia was RuralNet Associates, Ltd. Fieldwork and data preparation was managed and conducted by Stephen Tembo, Patrick Chilumba, Chozi Nkhata, and Rhoda Chiwele of RuralNet. Thanks to the data collection teams and supervisors listed on the next page. We acknowledge the contribution of the consultants who assisted in developing the data collection training and fieldwork.

This report was written by Lou Apicella, Katie Schenk, and Hena Khan of the Population Council. Quantitative data analysis was conducted by Lou Apicella and qualitative data analysis was conducted by Katie Schenk. Technical review was conducted by Naomi Rutenberg. Many thanks to Sherry Hutchinson for design and layout of the document. 


\section{QUANTITATIVE DATA COLLECTION PERSONNEL}

\section{Supervisors}

\section{Baseline 2005}

Patrick Chilumba, Geoffrey Siulemba, Kelvin Munjile, Rhoda Chiwele, Kalobwe Saya, Silimi Muyaka

\section{Midterm 2007}

Mutale Mwaba, Geoffrey Siulemba, Kelvin Munjile, Kachinga Phiri, Charity Mundia, Christopher Chitembo

\section{Endline 2009}

Martha Chooka-Manwachi, Kelvin Munjile, Kanyanta Musonda, Chozi Nkhata, Mary Nyirenda

\section{Data collectors}

\section{Baseline 2005}

Wonani Tinana, Moonde Sooka, Kyakilika Martha, Munkmba Njekwa, Chilumba Mukuka, Zulu Lameck, Nkwilimba Stanley, Lupupa Mwango, Kaliye Veronica, Chooka Martha, Lubinda Nasilele, Sichone David, Matanda Sara, Siakalima Daniel, Kabila Sitali, Mubambe Chippo, Miyoba Nixon, Sakala Tomothy, Chama Nonde, Kapumpe Kalenga, Kaweni Kabele, Lupiya Mubanga, Mambwe Kelvin, Nsangwa Ngwira, Chiluba B Chinyanta, Membe Joy, Mtonga Bruno, Kanyika Eucaria, Kasonso Nolia, Simeza Micheal, Chabwela Penias, Chingala Godfrey, Ng'uni Mutumbi, Nyambe E Mulima, Tembo Lawrence, Tembo Mavis

\section{Midterm 2007}

Zandile Makombe, Sarah Nalavwe, Tamani Mulenga, Brian Mphanja, Mambwe Kamuzyu, TemwanyJoshua Phiri, Malubu Maambo, Mwango Lupupa, Mupuwaliywa Mupuwaliywa, Mwika Mulaliki, Walumwega Mubitana, Namakau Mutumba, Lawrence Tembo, Tamara Mwandila, Peter Mwale, Stephen Chiwele, Chola Mwape, Mercy Zulu, Kelvin Mambwe, Brian Mwanza, Mwitwa Nkhuwa, Mutale Musonda, Elina Nambeye, Musouda Kanyanta, Lawrence Chileshe, Stephen Mwamba, Nancy Muhenga, Emeldah Mulenga, Elbe Kayange, Chalwe Mumba, Mofya Phiri, David Sichone, Mavis Tembo, Muthani F Phiri, Masauso Moses Phiri, Janet Tembo

\section{Endline 2009}

Humphery Mazanzi, Michael Kabaghe, William Mbalaso, Lusubilo Kabaghe, Patrick Nkhata, Chola Mwape, Lutangu Mubita, Walumweya Mubitama, Nchimunya, Brian Hapunda, Max Mupale, Kabila 
Sitali, Justine Munjile, Kayemba Mwila, Catherine Kalonga, Sarah Nalavwe, Miyoba Mweshi, Lawrence Tembo, Vincent Mwanza, Maggie Chansa, Hilton Makaya, Chanda Chibuta, Sammy Mutale, Elina Nambeye, Barbara Namwila, Andrew Chibangula, Stephen Mwamba, Aqual Morris, Mutale Mwaba, Joseph Kasense, Gome Nyirongo, David Sichone, Tamara Nkhata, Mabwibwi, Gabriel Banda, Mavis Tembo, Dalitso Tembo

\section{Training consultants}

Dr. Amos Banda, University of Zambia

Ms. Getrude Mwape, University of Zambia

Dr. Gregory Nshakankala, University Teaching Hospital 


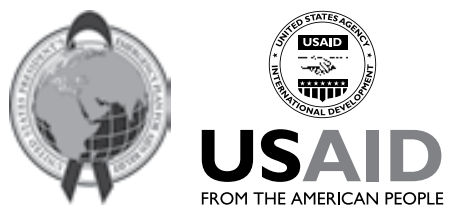

This study and final report were made possible by the President's Emergency Plan for AIDS Relief and the generous support of the American people through the United States Agency for International Development (USAID) under the terms of Cooperative Agreement No. 690-A-00-04-00251-00. The contents are the responsibility of Population Council and do not necessarily reflect the views of USAID or the United States Government.

\footnotetext{
1 Population Council The Population Council conducts research worldwide to improve policies, programs, and products in three areas: HIV and AIDS; poverty, gender, and youth; and reproductive health. www.popcouncil.org
}

Copyright (C) 2009. The Population Council Inc. Published in July 2009. Revised in January 2010.

Suggested citation: Apicella, Lou, Katie Schenk, and Hena Khan. 2010. "RAPIDS evaluation final report 2005-2009 key findings." Lusaka, Zambia: Population Council.

This document may be reproduced in whole or in part without permission of the Population Council provided full source citation is given and the reproduction is not for commercial purposes. 
46 RAPIDS Evaluation Final Report 2005-2009 Key Findings 



\section{(2) Population Council}

www.popcouncil.org

Suite 101, 1st Floor, Unit 1

La Belva Court, Plot 417

Chindo Road, Kabulonga

Lusaka 10101

Zambia

Tel: +260-211-262-665/6 